\title{
A review of challenges and opportunities of blockchain adoption for operational excellence in the UK automotive Industry
}

\begin{tabular}{|r|l|}
\hline Journal: & Journal of Global Operations and Strategic Sourcing \\
\hline Manuscript ID & JGOSS-05-2020-0024.R1 \\
\hline Manuscript Type: & Research Article \\
\hline Keywords: & $\begin{array}{l}\text { Blockchain, Operational excellence, Technological, Opportunities, } \\
\text { Management challenges }\end{array}$ \\
\hline Data Type: & Qualitative \\
\hline \multicolumn{2}{|l}{} \\
\hline
\end{tabular}




\title{
A review of challenges and opportunities of blockchain adoption for
} operational excellence in the UK automotive Industry

\begin{abstract}
Purpose - This paper aims to explore the challenges and opportunities of blockchain technology adoption from the lens of the TOE framework for operational excellence in the UK automotive industry context.

Design/methodology/approach- The research methodology of this study follows a systematic review approach, which analyses existing academic published research papers in the top 35 academic journals. There was no specific timeframe established for this study and shortlisting the articles through a set of used keywords. A sample of 71 articles was shortlisted and analysed to provide a discussion on technological and management challenges and opportunities of blockchain adoption from the lens of the TOE framework for operational excellence.

Findings- The findings of this study present significant theoretical and managerial implications and deep understanding for firms seeking to understand the challenges and opportunities of blockchain adoption for their operational excellence.

Research limitations/implication - Systematic literature approach was considered for the present study to explore existing academic papers on technological and management challenges and opportunities from the lens of TOE framework for operational excellence, whereas a more specified method meta-analysis can be considered for future research. The study has been explored in the UK automotive industry context, which has been considered as the limitation of generalization across countries and industries.
\end{abstract}

Originality/value - This paper represents the most comprehensive literature study related to the technological and management challenges and opportunities of blockchain from the TOE framework angle for operational excellence.

Keywords - Blockchain, Operational excellence, Technological and Management challenges and opportunities of Blockchain Adoption.

Article Classification: A literature review

\section{Introduction}

The UK automotive industry has become one of the main driving industries for employment as the "employees reported by signatories in 2017 increased by $7.5 \%$ to 113,500 , agency workers also accounted for $17.4 \%$, jobs that are dependent on the UK automotive industry 
manufacturing" (SMMT, 2019). It was revealed that the UK automotive industry is one of the key pillars that has transformed the UK economy (Bailey and Propris, 2017). For example, in July 2018 , it was reported that there was " $12.8 \%$ " increase in manufacturing commercial vehicles such as buses, trucks, vans, and coaches in the UK because of customers demand from overseas which was the driving output (SMMT, 2018a), which also contributed to the UK economy tremendously.

Despite the UK automotive industry economic contribution, there has been increasing pressure for UK carmakers to adopt technologies that can enhance their operations and supply chain due to the current trend of different technologies that are rapidly changing in the automotive industry (KPMG, 2017). To provide solutions to the current innovation challenges in this industry, blockchain technology was recommended as one of the technologies that can provide solutions to "seven key innovation opportunities", regarding the creation of new and superior customer experiences in the age of hyper convenience (SMMT, 2018b). It has been shown in the previous studies that were conducted over two decades that a lot of UK carmakers have attempted to enhance their supply chains operations such as delivery method and manufacturing processes (Caldwell and Smallman, 1996; Turner and Williams, 2005; Mortimer, 2005; Shaw, 1989). To support this commitment, empirical research conducted a few years ago and systematic literature review have also revealed that this industry has adopted various operations management approaches such as Japanese manufacturing model, in particular, Just-in-Time (JIT) manufacturing system (Turnbull et al. 1992), Japanese employment policies (Turnbull, 1988), total quality control (TQC) principles (Yusof and Aspinwall, 2001), supplier relations (Demirbas and Wilkinson, 2018), lean and agile production (Qamar and Hall, 2018; KPMG, 2017), team building via outdoor training (Lowe, 1991) without any concern about blockchain technology despite how blockchain has been recommended as one of the solutions to "seven key innovation opportunities" in the UK automotive industry (SMMT, 2018b) as stated earlier. Similarly, it was revealed in the report some of the largest car manufacturers in the world, including BMW and General Motors have joined software groups to create a new initative to use blockchain technology due how this industry is facing different innovative technologies (McGee, 2018). Therefore, this call for attention that needs to be focused on limited studies on blockchain technological and management challenges and opportunities in this industry within the UK context.

Blockchain is a technology that underpins bitcoin, is a distributed, decentralised, and public ledger structure that disintermediates third service provider in terms of transaction based on 
Peer-to-Peer (P2P) network (Nakamoto, 2008; Larios-Hernández, 2017; Chen, 2018). Empirical evidence found that blockchain technology is a value of technology in supply chain management to extend visibility and traceability, supply chain digitalisation and disintermediation, improved data security and smart contracts (Wang et al. 2019a). According to Larios-Hernández (2017) in specific contexts, blockchain can lower transactional costs when individuals informal networks are exploited by local usury or led into labour, as well as when formal banking is not an option. Mani and Chouk (2018) asserted that investing in blockchain technology may be of interest in enhancing operational safety. Blockchain technology is an innovative approach that can contribute to the enhancement of operational excellence (Upadhyay, 2020). For example, empirical evidence found that blockchain can contribute to the business process to automatic reduce cost and enhance operations efficiency (Oh and Shong, 2017; Holotius et al. 2019). Similarly, one of the findings of research conducted by Sanders et al. (2018) suggested that the adoption of blockchain technology is connected to the success of traceability and transparency in which customer demands in terms of delivery of products are met.

It was asserted that blockchain technology is a radical innovation (Holotius et al. 2019). The adoption, implementation, and use of blockchain technology are growing gradually in different areas such as airline sector (Ying et al. 2018), while some firms and manufacturers such as car manufacturers that include Toyota has started using blockchain in its internal operations (Kouhizadeh et al. 2020) Though there have been relatively few studies on blockchain technology conducted by different researchers in the UK (White, 2017; Wang et al. 2019a; Cole et al. 2019) context, while there are ample of studies outside the UK (Queiroz et al. 2019; Yin et al. 2019; Saberi et al. 2018; Kamble et al. 2019), in particular, in other industries such as financial institution (Oh and Shong, 2017; Meijer and R.W, 2016). Despite the exploration of blockchain challenges and opportunities research in other areas (AI-Saqaf and Seidler, 2017; Upadhyay, 2020), most importantly, despite the degree of studies on blockchain technology in the automotive industry outside the UK (Kang et al. 2017), and the degree of studies in predicting the future of applications of blockchain in business and management in the UK (White, 2017), there is still limited empirical and systematic review studies on technological and management challenges and opportunities of blockchain adoption from TOE theoretical angle for operational excellence in the UK automotive industry (Cole et al. 2019; Wang et al. 2019a). Though this might be due to the novelty of this technology. Therefore, the present study aims to fill this research gap by reviewing and providing evidence of technological and 
management challenges and opportunities blockchain adoption from the lense of TOE framework for operational excellence in the UK automotive industry. Additionally, it appears that comprehensive and systematic review study on technological and management challenges and opportunities of blockchain adoption for operational excellence outside the UK automotive industry has not received much attention in the academic literature compared with other innovation and management approaches such as supply chain management (Turner and Williams, 2005; Benito et al. 2013; Queiroz et al. 2019; Queiroz and Wamba, 2019), Lean Six Sigma (Habidin and Yusof, 2013; Swarnaker and Vinodh, 2016) etc.

Even though the academic researchers have agreed that blockchain technology will disrupt the business structure i.e status quo (Wang et al. 2019a; Clohessy and Acton, 2019; Treiblmaier, 2018; Gurtu and Johny, 2019; Boukis, 2019; Kouhizadeh et al. 2020), provide cybersecurity to supply chain (Min, 2019), in particular, to facilitate operational excellence (Moktadir et al. 2020), yet, there are still need to be aware of possible challenges facing blockchain technology (Min, 2019; Kher et al. 2020; Upadhyay, 2020; Ali et al. 2020; Vincent, 2020; Helliar et al. 2020) such as cybercrime (Chang et al. 2020a) or cyberattack (Biswas and Gupta, 2019) and its opportunities (Jianchao et al. 2020; Upadhyay, 2020; Herian, 2017) for operational excellence in the automotive industry. These challenges and opportunities are classified as technological and management challenges and opportunities and incoporated into TOE farmewoke. for a holistic understanding of firms that are not familiar with these challenges and opportunities Therefore, technological context includes blockchain technological challenges such as open network designs (O'Leary, 2017; O'Leary, 2018), security and privacy challenges (Upadhyay, 2020; Chang et al. 2020a), wasted resources or energy consumption (FrizzoBarker, et al. 2020; Chang et al. 2020a), lack of interoperability challenges (Upadhyay, 2020), scalability challenges (Min, 2019; Upadhyay, 2020; Chang et al. 2020a; Biswas and Gupta, 2019); blockchain technological opportunities include disintermediation of third-party service provider opportunities (Shermin, 2017; Manski, 2017; Herian, 2017; Upadhyay, 2020; Schuetz and Venkatesh, 2019), transaction cost reduction opportunities (Upadhyay, 2020), security opportunities (Kouhizadeh et al. 2021; Wang et al. 2019b); Organisational conext includes blockchain management opportunities such as knowledge sharing management opportunities (Li et al. 2018; Chang, et al. 2020a), supply chain management opportunities (Wang et al. 2019a), and new business model opportunities (Delafenestre, 2019; Tiscini et al. 2020;

Upadhyay, 2020); the blockchain management challenges that were revealed include lack of advanced level of blockchain technical expertise, and enviormntal conext includes government regulatory and legal issue that can affect the adoption of blockchain at the firm level 
(Upadhyay, 2020; Min, 2019; Manski, 2017; Herian, 2017; Orji et al. 2020; Biswas and Gupta, 2019). Even though these studies have explored challenges and opportunities of blockchain technology and even if a few of these studies (Upadhyay, 2020; Ali et al. 2020; Chang et al. 2020a; Kumar et al. 2020; Min, 2019; Queiroz, et al. 2019; Cole, et al. 2019) have laid a research foundation for the present study, exploring the technological and management challenges and opportunities of adoption from technological - organisational - environmental (TOE) angle for operational excellence in the automotive industry is yet to be explored (Kouhizadeh et al. 2021; Liu et al. 2020; Clohessy and Acton, 2019; Orji et al., 2020).

Technology - organisational - environmental (TOE) explains factors that affect the adoption of technology and likelihood (Tornatzky and Fleischer, 1990). TOE framework has been used to explore different issues in different industries (Orji et al. 2020), in particular, the automotive industry (Wang et al. 2020; Lin et al. 2018). The technological, organisational, and environmental (TOE) represented challenges/constraints and opportunities for technological innovation and influenced the technological innovation of the firm's level according to Tornatzky and Fleischer (1990). Therefore, this concept is appropriate to explore the challenges and opportunities of blockchain adoption (Clohessy and Acton, 2019). Other factors that are impacting technology adoption, which differs from common constructs of TOE framework such as top management (Puklavec et al. 2020), complexities (Orji et al. 2020) etc can be incorporated into technology - organisation - environment (TOE) framework (Nam et al. 2019; Aboelmaged, 2014). Therefore, the present study provides in-depth understanding into an analysis of information systems (IS) adoption by exploring 12 factors incorporating into the technology - organisation - environment (TOE) context to discuss technological and management challenges and opportunities of blockchain adoption based on the research published in the business and management academic journals for operational excellence in the UK automotive industry. In general, the key aim of the present study is to systematically review the existing academic literature on the technological and management challenges and opportunities of blockchain adoption to identify research topics that have been addressed, which can be considered for operational excellence in the UK automotive industry. Therefore, to achieve this objective the present study aims to address the following research question through a systematic literature review (SLR) (Srivastava, 2007; Tranfield et al. 2003; Denyer \& Tranfield, 2009): 
1. What are the technological and management challenges and opportunities of blockchain adoption from the lens of the TOE framework for operational excellence in the UK automotive industry?

The rest of this paper is structured as follow. Section 2 of this paper provides the theoretical foundation for the present topic at hand, section 3 explains systematic literature review methodology followed in this paper in detail, section 4 reports the findings based on the shortlisted sample articles from this study, section 5 discusses blockchain, operational excellence, blockchain technological challenges, blockchain management challenges, blockchain opportunities, and blockchain management opportunities. Section 6 is the conclusion of this paper, which highlights both limitations and future research direction of this paper.

\section{Theoretical Background}

\subsection{Technological - organisational - environmental (TOE)}

Different academic studies have shown that several ileories can be used to explore the challenges and opportunities of new technology aaop ${ }^{\text {: }}$.n (Fuchs et al. 2020; Egi, 2020; Dhirasasna et al. 2020) such as the technological - organis a or al - and environmental (TOE) framework that has been used frequently for challenges and $r_{n}$ nortunities of technology adoption (Abed, 2020; Maroufkhani et al. 2020), in particular, to unc'eist ind various challenges and barrier for blockchain adoption within supply chain management wor.ext (Kouhizadeh et al. 2021; Liu et al. 2020). Tornatzky and Fleischer (1990) developed Tevin ' :ngy organisational - environmental (TOE). TOE framework explains factors that af $\_$. t the adoption of technology and likelihood (Tornatzky \& Fleischer, 1990) such as blockchain adoption barriers and drivers (Kouhizadeh et al. 2021; Liu et al. 2020). The technolıgy organisation - environment (TOE) provide challenges and opportunities for technology innovation according to Tornatzky and Fleischer (1990). In their book, technology context 
represents the availability and the features of technological innovation; organisation context describes top management, the resources of the firm such internal tool and specialisation, huın`s apital size; and environment context refers to certain operational inhibitors and facilitat $\mathrm{C}^{\prime} \mathrm{s}$, 'mportantly, these include environment or government regulatory, infrastructures that include technology support by connecting to technology consultants in quality ICT.

Previous studies hav e used various technology adoption theories such as TAM, UTAUT etc as their basis to study tre shallenges and opportunities of technology adoption at the individual level (Li and Chang, 20 $\_$, Prtil et al. 2020). TOE framework takes a view of the organisation as a whole beyond the individ'ai perspective. Though this approach differs from the work of Kouhizadeh et al (2021) who use. th $^{1}$ TOE framework approach to explore the challenges and opportunities of blockchain adoption at $t^{2}:$ individual level. Largely, the TOE framework has been used at the firm level to understand the challenges/barriers and opportunities for technology adoption (Ali et al. 2020; Abed, $2{ }^{\prime}-U$ ) The adoption of blockchain by the firm is important since the adoption of technology is usually im plemented by the decision of the firm rather than the decision of a single employee. After alı, th, adoption of blockchain technology signifies a major investment for the firm. Though the diff $\lrcorner_{\wedge} 1 \mathrm{n}$ of innovation theory would have been considered for the present study, however, despite tne $r^{\prime}$ nularity of this theory it does not usually accommodate other constructs. Therefore, since th, pr ssent study aims at exploring challenges and opportunities of blockchain adoption for oper atir.al excellence in the UK automotive industry context by targeting the firm as a whole and siuce this theory is suitable at TOE framework to discuss technological and management opportunit iss of blockchain adoption for operational excellence.

\subsection{Blockchain Technology}

Blockchain technology was revealed as a technology that underpins Bitcoin in a white paper by Nakamoto (2008), the progress of blockchain literature and author productivity of 
blockchain in different areas have been reviewed and are increasing (Miau and Yang, 2018; Adams, et al. 2017; Chang, et al. 2020a). Blockchain is one of the transformative technologies transforming different industries across the globe (O'Dair and Beaven, 2017; O'Dair and Owen, 2019; Sanders et al. 2018; Diestelmeier, 2019; Zhang et al. 2020) such as financial sector (Scott et al. 2017; Cai, 2018; Zhang et al. 2020), fish industry (Tsolakis et al. 2020) in particular, the automotive industry (Kang, et al. 2017) in which researchers proposed "blockchain-based distributed framework" for the automotive industry (Sharma et al. 2018), and it has been examined for different areas such as supply chain, operations management etc. (Treiblmaier, 2018; Wang et al. 2019a; Thurner, 2018; Queiroz et al. 2019; Queiros and Wamba, 2019). The truth about blockchain is that it helps to make existing systems more efficient, and Ethereum smart contract technology allows developers to build applications to create a business that run themselves with distributed and decentralised profit margins, management, services according to Manski (2017).

There are various applications of blockchain technology, which can be used for achieving operational excellence. These applications of blockchain include blockchain-based smart contracts (Sheth and Subramanian, 2019), blockchain-based decentralised cryptocurrencies (Yuan and Wang, 2018), traceability in the supply chain (Behnke and Janssen, 2019), international payment (Ali et al. 2020) etc. According to Iansiti and Lakhani (2017)

"blockchain is a foundational technology: it has the potential to create new foundations for our economic and social systems". For example, exploration study shows the potential impact of blockchain technology enables a new system of value that will better support the dynamics of social sharing (Pazaitis et al. 2017) and change how people interact around the globe. Initially, Nakamoto (2008) presented blockchain as a technology that underpins Bitcoin, which is one of the cryptocurrencies to permit any two persons that are willing to transact directly with each other without requiring for a trusted third party or provider, for example, the trusted third 
parties that used to be required between two parties that are willing to transact with each other include banks or certification authorities (CA), legal practitioners, brokers etc (Iansiti \& Lakhani, 2017).

\subsection{Operational Excellence}

According to Dungan (2012) “operational excellence is one of today's key management themes for-profit and non-profit organisations". The meaning and the use of operational excellence is different from one scholar to another (Olhager and Person, 2006), from one company to another (Treacy and Wiersema, 1993; Power, 2013), and there are lots of different operational excellence models that had been built by different scholars (Edgeman, 2018; Sony, 2019). Similarly, they have been different academic published literature reviews on how operational excellence was originated (Sony, 2019; Olhager and Person, 2006).

Definitions of operational excellence differ from one scholar to another. For example, Treacy and Wiersema (1993) defined operational excellence as "the provision of reliable products or services to customers at competitive prices and delivered with minimal difficulty or inconvenience". Similarly, operational excellence in the recent study conducted by Cui et al. (2020) shows that "operational excellence is a management system designed to achieve customer value through innovation and technology development". They argued that operational excellence aims at continuously improving the process of operation and the effectiveness and efficiency of the industrial system. A lot of papers have suggested different methods of how operational excellence can be implemented and achieved in different industries. For instance, a study revealed that operational excellence can be the adoption of technological innovation for the reduction of operational cost and meeting customer demand (Santa et al. 2014). Similarly, different concepts such as "audit sheet" and "Lean Six Sigma" 
were suggested by Vrellas and Tsiotras (2015) for the implementation of operational excellence as one of the methods for solving problems. A research conducted by Cui et al. (2020) argued that operational excellence can be achieved through the internet of things (IoT) to improve supply chain collaboration.

As different researchers have conducted different studies for achieving operational excellence through the use of different approach such as "audit sheet" and Lean Six Sigma", in particular, the internet of things (IoT) to achieve operational excellence, there is still a limited study on exploration of blockchain adoption for operational excellence to understand its technological and management challenges and opportunities, in particular, in the automotive industry despite how the researchers have encouraged a study of blockchain technology "from an operations" viewpoint (Cole et al. 2019) and despite how it was revealed that operational excellence can be the adoption of technological innovation (Santa et al. 2014). Therefore, understanding the technological and management challenges and opportunities of blockchain adoption for operational excellence called for attention.

\section{Methodology}

The present study focuses on discussions and analyses of existing literature in business and management, to explore the challenges and opportunities of blockchain adoption and for operational excellence in the UK automotive industry context. There are several studies based on different methods in which various journals have published. For example, in the UK, empirical research conducted by White (2017) only focused on the future of blockchain applications without any concern about the challenges of blockchain adoption. Similarly, the present study finds related studies that were conducted by the researchers in the UK (Cole et al. 2019; Wang et al. 2019a). For example, various opportunities and challenges of blockchain for supply chain were explored by Cole et al. (2019) without any concern about the lack of interoperability, which is one of the blockchain challenges. Also, the drivers and

challenges/barriers of blockchain were identified by Wang et al. (2019a) within the supply chain in their research without any concern about open network design challenges. These two studies that were found in the UK have not explored this issue from the TOE framework angle 
despite the fact TOE framework has been used for barriers and drivers of blockchain adoption at the individual level in another country (Kouhizadeh et al. 2021).

Similarly, there have been some studies that have explored challenges (Upadhyay, 2020; Min, 2019; Manski, 2017; Herian, 2017; Biswas and Gupta, 2019; Frizzo-Barker et al. 2020; Chang et al. 2020a; O'Leary, 2018; O'Leary, 2017) and opportunities of the blockchain (Li et al. 2018; Chang et al. 2020a; Wang et al. 2019a; Delafenestre, 2019; Shermin, 2017; Manski, 2017; Tiscini et al. 2020; Upadhyay, 2020) in other countries, but these studies have only emphasised on a limited scope of blockchain challenges and opportunities and have not considered exploring this area for operational excellence in the automotive industry without any concern about TOE framework (Upadhyay 2020; Ali et al. 2020; Chang et al. 2020a; Kumar et al. 2020; Min, 2019). Therefore, it is fair to say that comparatively less study exists in the automotive industry to explore the challenges and opportunities of blockchain among automakers aiming to achieve operational excellence (Kouhizadeh et al. 2020). As blockchain technology promises to revolutionise business activities in the future, focuses on eliminating trusted third party between two people who are willing to transact together, and cutting cost for firms, calls for attention to be aware of the challenges and understanding of the opportunities of blockchain in the business operations. Understanding the basic blockchain technological and management challenges and opportunities of blockchain adoption from the TOE framework in the UK automotive industry for operational excellence is a gap in the literature that this study aims to fill by systematically review existing academic journal articles(Cole et al. 2019; Wang et al. 2019a).

Systematic literature review means exploring existing and selected journal articles from various databases and sources for research study purposes (Hohenstein et al. 2014) and is being used as well-organised methods for accomplishing wide literature review (Agarwal et al. 2017). Several systematic literature review papers have been published in business and management focused on various significant topics (Steininger, 2019; Queiroz et al. 2019; Cai, 2018). According to Tranfield et al. (2003) "systematic review provides a means for practitioners to use the evidence provided by research to inform their decision”. A systematic literature review assists to recognise the theoretical content of the field and it can add to theory development 
(Atewolohun et al. 2017; Nolan and Garavan, 2016). Recently, there have been limited literature review papers within the area of related research (Cole et al. 2019; Wang et al. 2019a). For example, Miau and Yang (2018) selected articles ranging from 2008 to 2017, resulting in a timeframe of 9 years for a blockchain literature review. Recently, 27 peer-reviewed journals in blockchain between 2008 and 2018 were reviewed and analysed by Queiroz et al. (2019). While a systematic literature review was conducted by Wang et al. (2019a) between the periods of December 2017 and January 2018. The researchers selected 24 published articles for understanding blockchain for the future supply chain. As stated earlier, there is a limited study of blockchain technological and management challenges and opportunities for operational excellence (Upadhyay, 2020; Ali et al. 2020; Chang et al. 2020a; Kouhizadeh et al. 2021 Cole et al. 2019; Wang et al. 2019a), in particular, in the automotive industry (Culot et al. 2020). Therefore, it seems proper to address this research gap due to the report, discussion, and concerns in adopting cutting-edge technologies such as blockchain in the UK automotive industry(SMMT, 2018b) as a report by the UK government has predicted that the adoption of blockchain technology would play a significant role in the UK where the technology might transform "financial markets, supply chains, customer and business-to-business services, and publicly-held registers" (Government Office for Science, 2016).

A systematic literature review approach was adopted based on collecting and analysing a set of published academic journal articles (Chugani et al. 2017; Queiroz et al. 2019). The present study aims to follow a related methodology and structure of selected articles from academic journals, which related to the works of Chugani et a.l (2017), Garza-Reyes (2015), Tian et al. (2018), Jensen, (2012), Strivastava (2007). However, based on these indicated studies, the method of analysis comprises five steps that have been used in the previous study (Jensen, 2012). Following this systematic process guarantees an effective and well-organised review. Therefore, these five steps are adapted from the published academic journal articles for this 
study (Srivastava, 2007; Jensen, 2012). These five steps include (1) defining the unit of analysis, (2) classification context, (3) material evaluation, (4) collecting publications, and (5) delimiting the field. These steps are shown in Table 1. Similarly, starting from the research question to the discussion of the research findings will also be based on the systematic review process of Tranfield et al. (2003).

Table 1. Summary of research methodology

Unit of analysis

Classification context

\section{Material evaluation}

\section{Collection of publications}

\section{Delimiting the field}

Selected journals

1.

2.

3.

4.

5.

6.

7.

8.

9.

10.

11.

12.

13.

14.

15.

16.

17.

18.

19.
The unit of analysis in this study is based on the exploration of existing academic research articles through a systematic literature review search

The articles used in the present study are structured and categorised based on the five contexts: First, classification of academic articles according to the published journal, second; classification of numbers of published journal articles found on the blockchain, blockchain technological challenges, blockchain management challenges, blockchain technological opportunities, and blockchain management opportunities; third; classification of the used articles into model approach context, blockchain application context, main theoretical approach, author, and the year, fourth; this classification was based on the publication year of the articles, while the fifth classification was based on the categorization of blockchain application in different industries, the year, and the number of articles found in the present study. The present study analysed all selected articles within the classification context described above.

The present research searched for articles based academic journals by using the keywords 'Blockchain', 'Blockchain Technological Challenge', 'Blockchain

Management Challenges', 'Blockchain Technological Opportunities', and

'Blockchain Management Opportunities' in the abstract and the main body of the searched articles. The criterion used to search for articles includes English academic published peer-reviewed article based academic journals and by using a list of Association of Business School (ABS) Journal Quality Guide from 2010 to 2018 to select academic journals and using a few appropriate good journals that are non- ABS journals.

Articles that did not provide references to academic sources or viewpoints were excluded.

Accounting and Finance

British Food Journal

Business Horizons

Computers and Industrial Engineering

Decision Sciences Journal

Energy Policy

Foresight

Harvard Business Review

IEEE Transactions on Industrial Informatics (non-ABS Journal)

IEEE Transactions on Systems Man and Cybernetics Part C Industrial Management and Data Systems

Information Technology and People

International Journal of Information Management

International Journal of Production Economics

International Journal of Production Research

International Journal of Retail and Distribution Management

Intelligent Systems in Accounting, Finance and Management

Journal of Business Research

Journal of Business Logistics

Journal of Economics and Business 
20.
Journal of Enterprise Information Management Journal of Financial Economics Journal of Financial Regulation and Compliance Journal of Management Information Systems Journal of Manufacturing Technology Management Journal of Service Management Management Decision Managerial Finance Production Planning and Control Strategic Change Supply Chain Management: An International Journal Systems Research and Behavioral Science Technology Analysis and Strategic Management Technological Forecasting and Social Change Transportation Research Part C: Emerging Technologies

71 academic articles were thoroughly searched from selected academic journals and considered for the present

\subsection{Journal selection}

It has been acknowledged in the academic settings across the globe that some journals are of higher quality than other journals (ABS, 2010; ABS, 2015; ABS, 2018). The present study selected journal based ABS Journals Quality Guide because it provides broad coverage of journals; has a high degree of external and internal reliability; is sensitive to minor variations in journals ratings and is widely accepted as a fair means of the ranking journal with its user group (Morris et al. 2009). Though other good academic non-ABS journals that are appropriate for the area of study were considered and selected as well. This study does not have any limited timeframe for the reviewing of existing published academic articles due to the inadequate articles and available information on the comprehensive topic area in blockchain technological and management challenges and opportunities in operational excellence due to the novelty of blockchain technology. To ensure high and strong quality literature reviewed in the present study, only published academic journal articles from the reliable source were selected and focused on peer-reviewed English-language articles that include journals on databases such as Emerald Insight, Taylor and Francis, Wiley Online Library, Elsevier, and IEEE Xplore. Only one non-ABS journal was selected in the present study, which is IEEE Transactions on Industrial Informatics journal. This journal was incorporated because the academic articles in this journal were significant to the present study and generally, this selected journal is an academic and popular journal for research. A total of 35 journals were selected for the present study. Figure 1 shows the process and the shortlisted journals for the present study are shown in (Table 1). Shortlisting through the use of keywords method, which is as an effective way of 
shortlisting that has been adopted in different studies (Tang and Musa, 2011; Chugani et al. 2017; Jensen, 2012) was used in the present research.

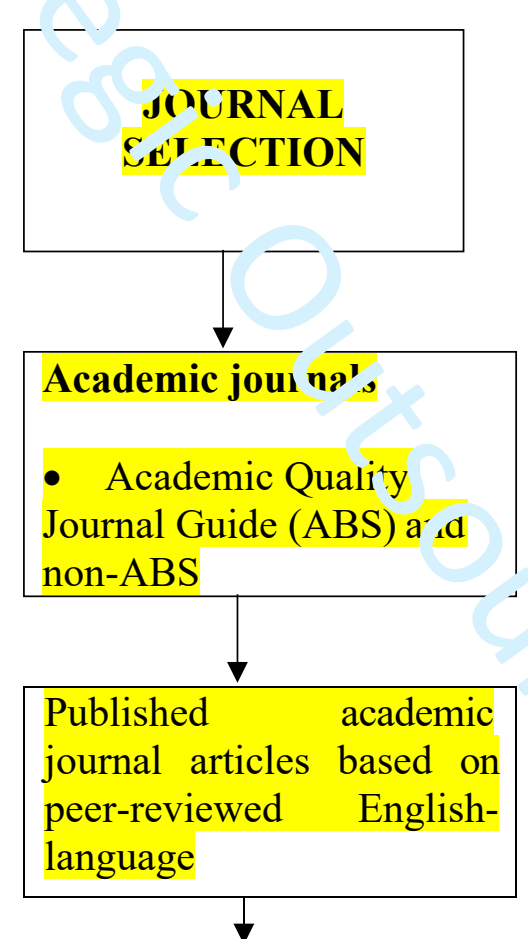

\section{Databases}

Wiley Online Library

Taylor and Francis

Havard Business Review

IEEE Explore

Elsevier

Emerald Insight

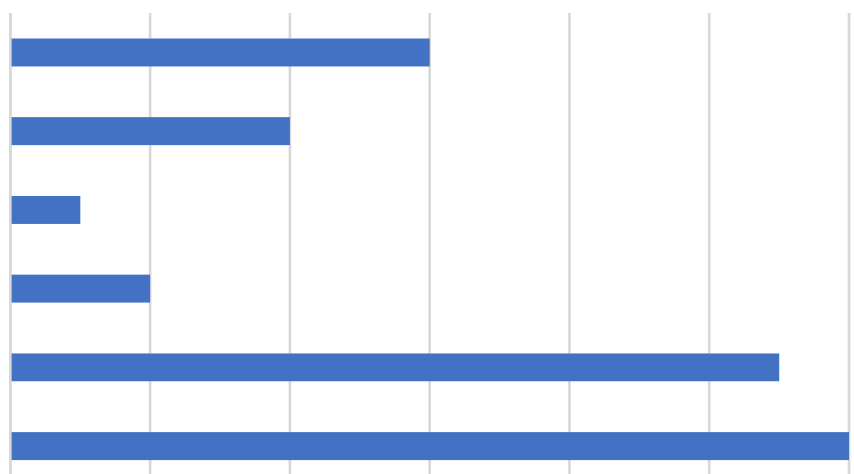

$\begin{array}{llllllll}0 & 2 & 4 & 6 & 8 & 10 & 12 & 14\end{array}$

Number of Academic Journals

Figure 1: The process of the selection of the journal (Source: Designed by the authors)

\subsection{Selection of articles}

As stated earlier, there was no timeframe set for the present study due to the few numbers of articles available on the present research topic due to the novelty of blockchain. All related articles to the present study were selected and employed from selected academic journals. To 
search for articles in the journals, five searches were performed in the present study, which includes, first with the title or keywords by using the keyword "blockchain" and later added blockchain to the remaining keywords such as technological challenges, management challenges, technological opportunities, and management opportunities to the blockchain, which resulted to the use of keywords 'blockchain management challenges', 'blockchain technological challenges', 'blockchain management opportunities', and 'blockchain technological opportunities' in the abstract of the articles and main body of the articles. The first search of the results of the number of articles at the time of searching is summarised in Table 2 and shows the number of articles that were found in the selected journals that are related to the keywords, which were used for the search. For example, when searching was performed on the search engine with the keywords 'Blockchain' on the databases such as Wiley Online Library within the subject of business and management, only 3 articles were found in the Intelligent Systems in Accounting, Finance and Management journal. While 23 articles were found in the Strategic Change journal.

Since a lot of numbers of articles on Blockchain Technology were found in the journals, the search went further by combining and filtering with the keywords 'Blockchain Management Challenges', the number of articles was reduced drastically. For example, Intelligent Systems in Accounting, Finance and Management journal yielded 2 articles when keywords

"Blockchain Technological Challenges" was placed in the search engine. While only 1 article likewise appeared when the use of keywords 'Blockchain Technological Challenges' was applied under the same journal. Additionally, only 1 article appeared under the same journal when the keywords 'Blockchain Technological Opportunities' in the search engine. Hence, the abstracts and the main body of the articles were scanned for relevance to blockchain technological and management issue since several academic articles that were shortlisted are not comprehensively related to the topic of the present study, importantly regarding the Blockchain Technological and Management Challenges and Opportunities for Operational Excellence, where the keyword "Blockchain" refers to a distributed database for digital transactions without a trusted third service provider such as a bank to authenticate transaction between two parties that are willing to do business. During the search of the articles in the journals, there were some of the same academic articles that appeared for different keywords that were used. For example, Strategic Change journals yielded some of the same academic articles for 'Blockchain Management Challenges' and Blockchain Management 
Opportunities." Hence, it was compulsory to explore and filter the articles and thoroughly select appropriate articles for the sample of the present study.

After an inclusive search and consideration of articles, a sample size of 70 academic articles was finalised and considered for the present study. For an effective analysis, consideration of the sample size of academic articles differs from one study to another (Natalicchio et al. 2017; Zimmermann et al. 2016). In the present study, the number of articles was limited to 71 articles. All 69 articles were used to include the sample. Hence, a sample size of 71 articles was explored, finalised, and considered from 35 academic journals for the analysis of the present study. 


\begin{tabular}{|c|c|c|c|c|c|}
\hline No,$\cdots n a !$ & Blockchain & $\begin{array}{l}\text { Blockchain } \\
\text { Technological } \\
\text { Challenges }\end{array}$ & $\begin{array}{l}\text { Blockchain } \\
\text { Management } \\
\text { Challenges }\end{array}$ & $\begin{array}{l}\text { Blockchain } \\
\text { Technological } \\
\text { Opportunities }\end{array}$ & $\begin{array}{l}\text { Blockchain } \\
\text { Management } \\
\text { Opportunities }\end{array}$ \\
\hline 1. Accounting and Finance & 5 & 3 & 3 & 4 & 3 \\
\hline 2. British Food Journal & 1 & 1 & 1 & 0 & 0 \\
\hline 3. Business Horizons & 13 & 6 & 11 & 6 & 10 \\
\hline 4. Computers and Industrial Engineering & 17 & 8 & 13 & 9 & 12 \\
\hline 5. Decision Sciences Journal & 12 & 11 & 9 & 5 & 5 \\
\hline 6. Energy Policy & 10 & 5 & 9 & 6 & 9 \\
\hline 7. Foresight & 12 & 15 & 12 & 9 & 7 \\
\hline 8. Harvard Business Review & 10 & 4 & 9 & 4 & 7 \\
\hline 9. IEEE Transactions on Industrial Informatics & 25 & 0 & 2 & 0 & 0 \\
\hline 10. IEEE Transactions on Systems Man and Cybernetics Part $C$ & 9 & 0 & 1 & 0 & 0 \\
\hline 11. Industrial Management and Data Systems & 6 & 6 & 6 & 4 & 4 \\
\hline 12. Information Technology and People & 13 & 9 & 8 & 5 & 3 \\
\hline 13. International Journal of Information Management & 42 & 27 & 16 & 26 & 36 \\
\hline 14. International Journal of Production Economics & 24 & 23 & 16 & 23 & 14 \\
\hline 15. International Journal of Production Research & 18 & 17 & 17 & 14 & 14 \\
\hline 16. International Journal of Retail and Distribution Management & 9 & 3 & 3 & 8 & 3 \\
\hline 17. Intelligent Systems in Accounting, Finance and Management & 3 & 3 & 3 & 4 & 4 \\
\hline 18. Journal of Business Research & 21 & 14 & 18 & 15 & 20 \\
\hline 19. Journal of Business Logistics & 14 & 10 & 11 & 13 & 14 \\
\hline 20. Journal of Economics and Business & 5 & 3 & 4 & 4 & 4 \\
\hline 21. Journal of Enterprise Information Management & 12 & 23 & 12 & 11 & 23 \\
\hline 22. Journal of Financial Economics & 3 & 0 & 2 & 0 & 2 \\
\hline 23. Journal of Financial Regulation and Compliance & 15 & 2 & 4 & 2 & 1 \\
\hline 24. Journal of Management Information Systems & 23 & 26 & 19 & 17 & 16 \\
\hline 25. Journal of Manufacturing Technology Management & 20 & 4 & 6 & 5 & 4 \\
\hline 26. Journal of Service Management & 7 & 7 & 789 & . & 7 \\
\hline 27. Management Decision & 12 & 2 & 1 & 1 & 1 \\
\hline 28. Managerial Finance & 14 & 9 & 4 & 5 & 3 \\
\hline 29. Production Planning and Control & 20 & 19 & 19 & 20 & 20 \\
\hline 30. Strategic Change & 23 & 19 & 10 & 10 & 10 \\
\hline 31. Supply Chain Management: An International Journal & 5 & 5 & 5 & 4 & 4 \\
\hline 32. Systems Research and Behavioral Science & 123 & 9 & 23 & 11 & 11 \\
\hline 33. Technology Analysis and Strategic Management & 3 & 5 & 5 & 4 & 4 \\
\hline 34. Technological Forecasting and Social Change & 15 & 17 & 15 & 16 & $14 \div$ \\
\hline 35. Transportation Research Part C: Emerging Technologies & 3 & 0 & 1 & 0 & 1 \\
\hline
\end{tabular}


Table 2. Number of articles found in the first search

Source: Design by the authors

\subsection{Articles Categorisation}

The reviewed papers in the present study are based on the work of different authors that have previously discussed and analysed blockchain technology challenges and opportunities. The classification of the articles was guided by the works of Wong et al. (2012), Queiroz et al. (2019), and Chugani et al. (2017), while this method was used in the work of Chugani et al. (2017). The same method was used for the present study to classify blockchain, blockchain technological and management challenges and opportunities research by first categorised the articles according to the academic published journals to agree on which academic journals published more information around blockchain technological and management challenges and opportunities based on the results of business and management search engine tools. The evidence in the present study shows that the International Journal of Information Management journal contributes 11 published articles to this area. This may be because articles in this journal discussed blockchain technology challenges and opportunities profoundly and as such hold large suitability towards the present study. Similarly, the Strategic

Change Journal contribute an important number of 8 published articles to the area, while the rest of the remaining journals contribute with a limited number of articles in this area.

The second categorisation of the articles was based on the numbers of articles found on the Blockchain Technological and Management Challenges and Opportunities. This allows us to assume which method was extensively discussed in academic literature in the present study. 
Blockchain

Blockchain Management Challenges

Blockchain Management Opportunities

Figure 2 Categorisation of article (Source: Designed by the authors) 
International Journal of Information Management

Strategic Change

Technological Forecasting and Social Change Supply Chain Management: An International Journal Intelligent Systems in Accounting, Finance and Management Computers and Industrial Engineering International Journal of Production Economics

Technology Analysis and Strategic Management International Journal of Production Research Industrial Management and Data Systems IEEE Transactions on Industrial Informatics Business Horizons

Production Planning and Control Journal of Business Research Systems Research and Behavioral Science Managerial Finance Management Decision Journal of Service Management International Journal of Retail and Distribution Management Journal of Manufacturing Technology Management Journal of Management Information Systems Journal of Financial Regulation and Compliance

Journal of Financial Economics Journal of Enterprise Information Management Journal of Economics and Business Journal of Business Logistics

Transportation Research Part C: Emerging Technologies Information Technology and People IEEE Transactions on Systems Man and Cybernetics Part C

Harvard Business Review

Foresight

Energy Policy

Decision Sciences Journal British Food Journal Accounting and Finance ace

\section{=}

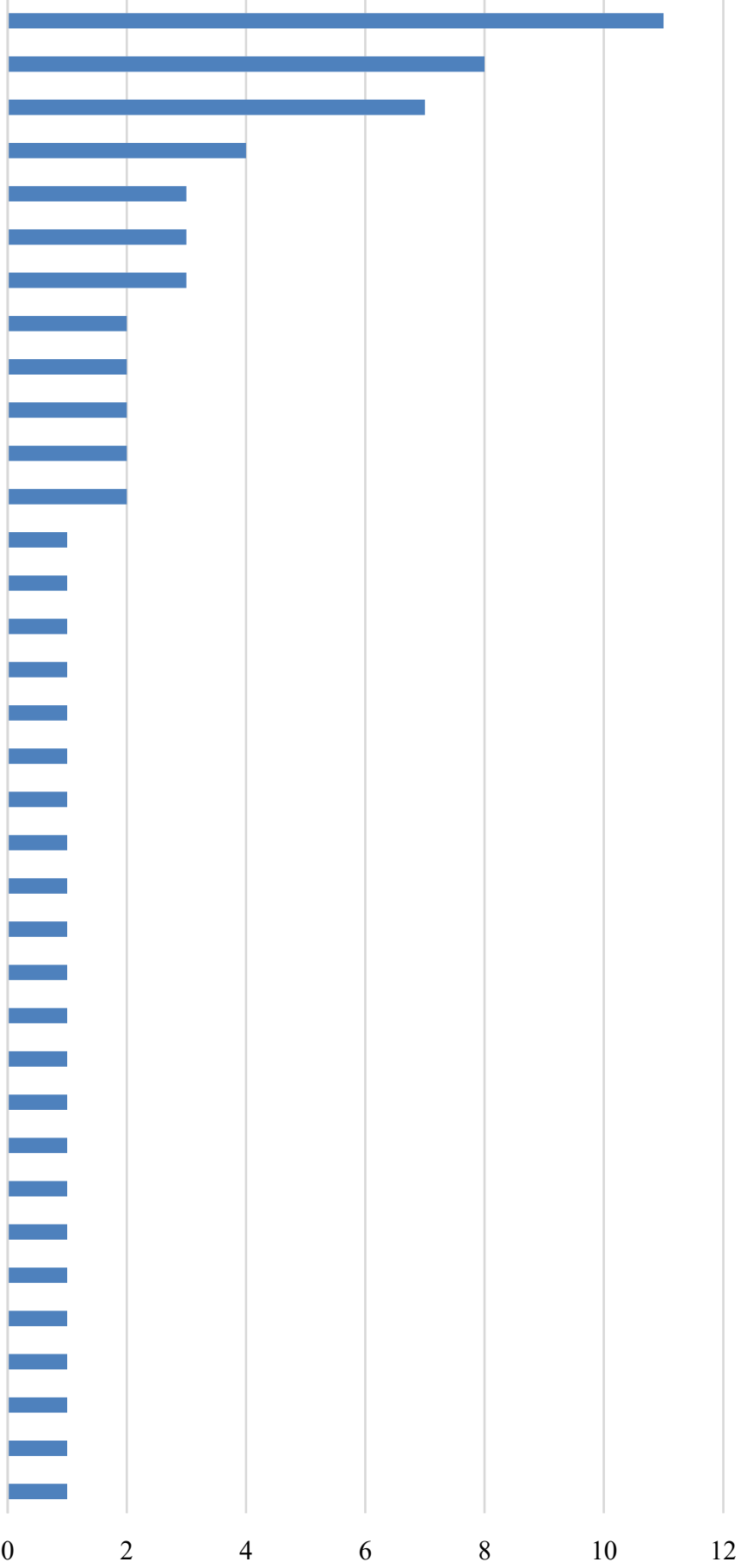

Number of Articles

Figure 2 shows that blockchain management challenges received more attention compare to blockchain technological challenges. This perhaps might be because the technology is still in its early stage or a lack of expertise (Kumar et al. 2020; Upadhyay, 2020; Min, 2019; Morkunas 
et al. 2019), lack of many participants (Helliar et al. 2020), or because a large number of blockchain technology has yet to be adopted (Morkunas et al. 2019), which made blockchain management challenges received more attention compared to its blockchain technological challenges. Whereas blockchain technological opportunities received more attention compared to blockchain management opportunities. As blockchain technological opportunities received more attention than blockchain management opportunities might be as a result that blockchain aims to disintermediary third service provider (Ali et al. 2020; Min, 2019) to reduce transaction cost among two parties that are willing to engage in business (Nakamoto, 2008; Morkunas et al. 2019; Bhaird et al. 2019). Though one of the blockchain management opportunities aims to manage the cost of operation (He et al. 2018). These challenges and opportunities call for research to be conducted in blockchain for a deeper understanding of these challenges and opportunities before its adoption by the UK carmakers for firms aiming to achieve operational excellence.

The third categorisation of articles separates the articles found in the present study into model approach context, blockchain application context, main theoretical approach, author, and the year of publication. This classification is based on the works of Queiroz et al. (2019), Chugani, et al (2017), and Wong et al. (2012). For example, some articles discussed blockchain challenges and exclusively rely on applications of blockchain to give details of a phenomenon. This study placed those articles under "blockchain application context". Some articles solely rely on using certain research approaches such as the Delphi study approach for blockchain to investigate certain issues, this study likewise placed those articles under "main theoretical approach". The articles that used model such as the business model with blockchain, such model was placed under the "model approach context". While the authors and the year of the article's publication were placed under the author and the year category. The third 
categorisation went further to categorise authors who indicated blockchain challenges and opportunities in their work and the area they addressed.

The fourth categorisation of articles was based on the year of selected articles for this study were published. However, this method was adapted based on the works of Garza-Reyes (2015) and Chugani et al. (2017), which has been adopted in different academic published studies (Chugani et al. 2017). This is crucial in this study to show recent articles that have been published around this study and it shows if this study is based on recent information or investigation of academic scholars. The results in the graph of this study show evidence that most of the articles on blockchain were published in 2017, 2018, 2019, and 2020 which indicated research of a good formulation on a recent study. Though only one article published in 2021.

The final categorisation, which is the fifth categorisation was adapted from the works of Queiroz et al. (2019) to categorise blockchain application in different industries, the year, and the number of articles that were found in this study.

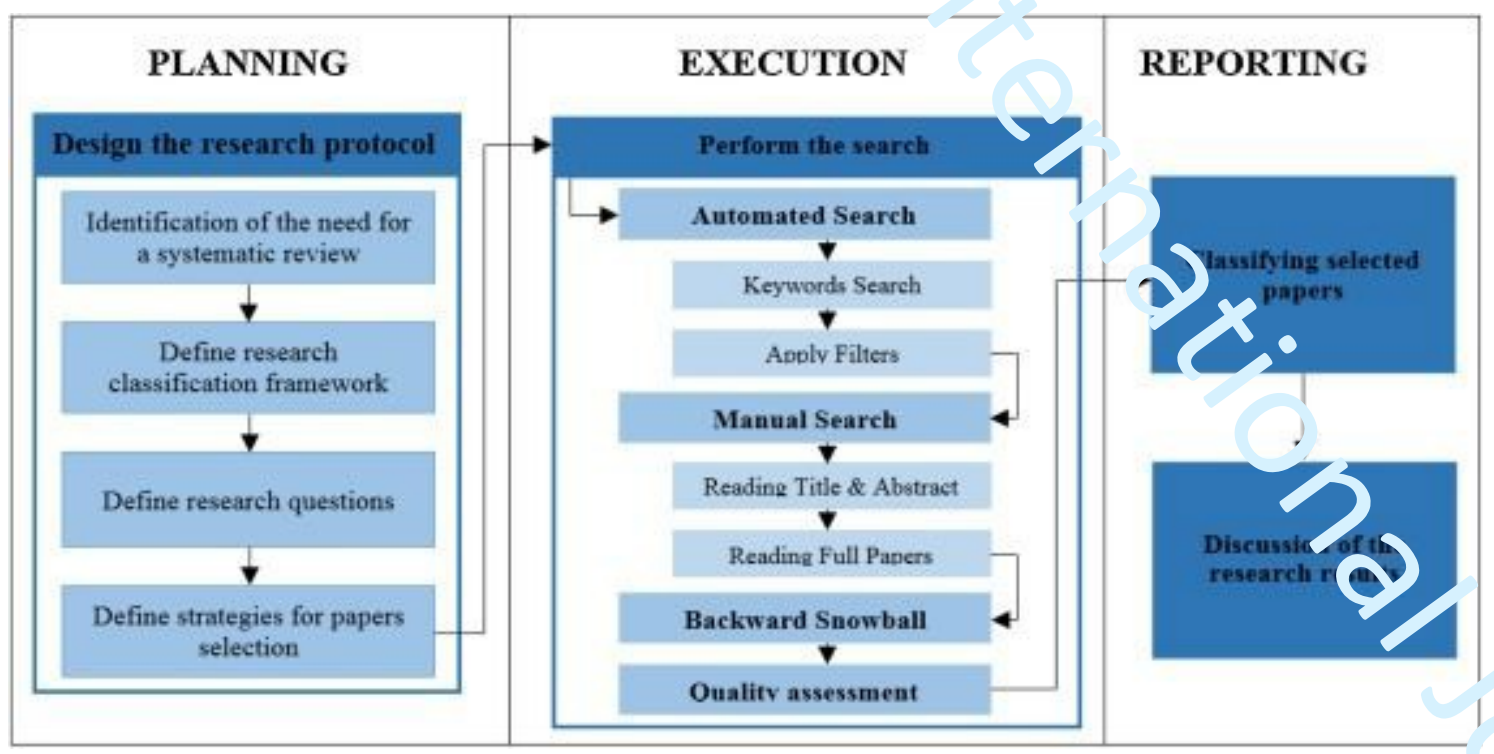

Figue 3: Process for systematic review study (Source: Designed by the authors) Sources: Adapted from (Tranfield et al. 2003; Ali et al. 2020) 


\section{Findings}

This study aims to explore blockchain technological and management challenges and opportunities in operational excellence. To achieve this aim, 69 articles from the top 35 journals were considered and shortlisted after systematic research in Error! Reference source not found.

Table 3. Shortlisted final sample of articles

\begin{tabular}{|c|c|c|c|c|c|}
\hline Keywords & $\begin{array}{l}\text { Blockc } \\
\text { hain }\end{array}$ & $\begin{array}{l}\text { Blockch } \\
\text { ain } \\
\text { Manage } \\
\text { ment } \\
\text { Challen } \\
\text { ges }\end{array}$ & $\begin{array}{l}\text { Blockch } \\
\text { ain } \\
\text { Technol } \\
\text { ogical } \\
\text { Challeng } \\
\text { es }\end{array}$ & $\begin{array}{l}\text { Blockch } \\
\text { ain } \\
\text { Manage } \\
\text { ment } \\
\text { Opportu } \\
\text { nities }\end{array}$ & $\begin{array}{l}\text { Blockch } \\
\text { ain } \\
\text { Technol } \\
\text { ogical } \\
\text { Opportu } \\
\text { nities }\end{array}$ \\
\hline 1. Accounting and Finance & 1 & 0 & 0 & 0 & 0 \\
\hline 2. British Food Journal & 0 & 0 & 0 & 1 & 0 \\
\hline 3. Business Horizons & 0 & 0 & 0 & 0 & 1 \\
\hline 4. Decision Sciences Journal & 0 & 1 & 0 & 0 & 0 \\
\hline $\begin{array}{l}\text { 5. Computers and Industrial } \\
\text { Engineering }\end{array}$ & 0 & 2 & 0 & 0 & 0 \\
\hline 6. Energy Policy & 1 & 0 & 0 & 0 & 0 \\
\hline 7. Foresight & 1 & 0 & 0 & 0 & 0 \\
\hline 8. Harvard Business Review & 0 & 0 & 0 & 0 & 1 \\
\hline $\begin{array}{l}\text { 9. IEEE Transactions on Industrial } \\
\text { Informatics }\end{array}$ & 2 & 0 & 0 & 0 & 0 \\
\hline $\begin{array}{l}\text { 10. IEEE Transactions on Systems Man } \\
\text { and Cybernetics Part C }\end{array}$ & 1 & 0 & 0 & 0 & 0 \\
\hline $\begin{array}{l}\text { 11. Industrial Management and Data } \\
\text { Systems }\end{array}$ & 0 & 1 & 0 & 1 & 0 \\
\hline 12. Information Technology and People & 0 & 10 & 0 & 0 & 0 \\
\hline $\begin{array}{l}\text { 13. International Journal of Information } \\
\text { Management }\end{array}$ & 2 & 5 & 2 & 0 & 2 \\
\hline $\begin{array}{l}\text { 14. International Journal of Production } \\
\text { Economics }\end{array}$ & 0 & 1 & 1 & 0 & 1 \\
\hline $\begin{array}{l}\text { 15. International Journal of Production } \\
\text { Research }\end{array}$ & 0 & 0 & 1 & 1 & 0 \\
\hline $\begin{array}{l}\text { 16. International Journal of Retail and } \\
\text { Distribution Management }\end{array}$ & 0 & 0 & 0 & 1 & 0 \\
\hline $\begin{array}{l}\text { 17. Intelligent Systems in Accounting, } \\
\text { Finance and Management }\end{array}$ & 0 & 2 & 1 & 0 & 0 \\
\hline 18. Journal of Business Research & 0 & 1 & 0 & 0 & 0 \\
\hline 19. Journal of Business Logistics & 0 & 1 & 0 & 0 & 0 \\
\hline 20. Journal of Economics and Business & 0 & 0 & 0 & 0 & 1 \\
\hline $\begin{array}{l}\text { 21. Journal of Enterprise Information } \\
\text { Management }\end{array}$ & 0 & 0 & 1 & 0 & 0 \\
\hline 22. Journal of Financial Economics & 0 & 1 & 0 & 0 & 0 \\
\hline
\end{tabular}


23. Journal of Financial Regulation and Compliance

24. Journal of Management Information Systems

25. Journal of Manufacturing Technology Management

26. Journal of Service Management

27. Management Decision

28. Managerial Finance

29. Production Planning and Control

30. Strategic Change

31. Supply Chain Management: An International Journal

32. Systems Research and Behavioral Science

33. Technology Analysis and Strategic Management

$\begin{array}{lllll}0 & 1 & 0 & 0 & 0 \\ 0 & 0 & 1 & 0 & 0\end{array}$

34. Technological Forecasting and Social Change

35. Transportation Research Part $C$ : Emerging Technologies

$\begin{array}{lllll}0 & 1 & 0 & 0 & 0 \\ 0 & 1 & 0 & 0 & 0 \\ 0 & 0 & 0 & 0 & 1 \\ 1 & 0 & 0 & 0 & 0 \\ 0 & 0 & 0 & 1 & 0 \\ 3 & 2 & 2 & 0 & 1 \\ 2 & 1 & 0 & 0 & 1 \\ 1 & 0 & 0 & 0 & 0 \\ 0 & 0 & 0 & 0 & 2 \\ 1 & 3 & 1 & 0 & 2 \\ 0 & 0 & 0 & 1 & 0\end{array}$


International Journal of Information Management Strategic Change

Technological Forecasting and Social Change Supply Chain Management: An International Journal Intelligent Systems in Accounting, Finance and Management Computers and Industrial Engineering International Journal of Production Economics

Technology Analysis and Strategic Management International Journal of Production Research Industrial Management and Data Systems IEEE Transactions on Industrial Informatics Business Horizons

Production Planning and Control Journal of Business Research Systems Research and Behavioral Science Managerial Finance Management Decision Journal of Service Management International Journal of Retail and Distribution Management Journal of Manufacturing Technology Management Journal of Management Information Systems Journal of Financial Regulation and Compliance

Journal of Financial Economics Journal of Enterprise Information Management Journal of Economics and Business Journal of Business Logistics

Transportation Research Part C: Emerging Technologies Information Technology and People IEEE Transactions on Systems Man and Cybernetics Part C

Harvard Business Review

Foresight

Energy Policy

Decision Sciences Journa British Food Journal Accounting and Finance Accounting and Finance

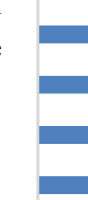

0

$$
2
$$

Number of Articles

Figure 3. Categorisation of number of articles in journal publication (Source: Designed by the authors)

Figure 3 shows the distribution of journals in this study shows that most papers that were published around the area of blockchain technological and management challenges and 
opportunities are recent papers. This indicates that blockchain has become an important area for study.

Findings show that part of the objectives of blockchain technology is to transform operations of supply chain management, to enhance product safety and security, to improve quality management; to reduce the cost of supply chain transactions etc (Cole et al. 2019). Likewise, this study found that managers that consider blockchain challenges before aiming to adopt this technology are considering the impact of blockchain outcome on their operations (Oh and Shong, 2017), while managers that are considering in adopting blockchain to make use of its opportunities are aiming to achieve operational excellence (Yeoh, 2017; Angelis and da Silva, 2019). Companies that adopt blockchain and make use of the blockchain opportunities are considered to achieve operational excellence (Cole et al. 2019). This is supported by the research conducted by Kamble et al. (2019). Kamble et al. (2019) implied that blockchain would improve supply chain effectiveness. Blockchain technological challenges include hacking, which it can occur as a group of miners temporarily control $50 \%$ of the network's mining hash-rate, which is the measurement of a unit of the processing power of a network of nodes that power a blockchain (Wang et al. 2019a) and one of the blockchain management challenges include limited knowledge of blockchain that most managers of companies lack, which is one of the barriers for them to adopt and implement blockchain technology (Angelis and da Silva, 2019). The findings of the present study on blockchain technological opportunities reveal that not only it will protect theft of cryptocurrency (Mahmoud et al. 2019), but it will create a new business model (Oh and Shong, 2017). Additionally, one of the blockchain management opportunities is to reduce the cost of the transactions, which ensures the safety of data, it can help operations and supply chain to detect unethical suppliers and counterfeit products etc (Saberi et al. 2018). Figure 4 shows the categorisation of articles according to year of publication 
1. Accounting and Finance

\begin{tabular}{ll} 
Crowdfunding & \\
\hline & Blockchain traceability and \\
transparent system
\end{tabular}

Context

2. British Food Journal

3. Business Horizons

4. Computers and Industrial Engineering

\section{Decision Sciences Journal}

6. Energy Policy

7. Foresight

8. Harvard Business Review

9. IEEE Transactions on Industrial Informatics

Blockchain

Systematic Review

Cai

Survey and interview study

$\begin{array}{lllllr}\begin{array}{l}\text { Risk } \\ \text { management/security } \\ \text { perspectives }\end{array} & \begin{array}{l}\text { Smart contracts, asset } \\ \text { tracking, cybersecurity }\end{array} & \text { Blockchain } & \begin{array}{l}\text { Review/conceptual } \\ \text { framework }\end{array} & \text { Min } & 2019 \\ \begin{array}{l}\text { Business Model } \\ \text { DEMATEL technique }\end{array} & \text { Private and public blockchain } & \text { Blockchain } & \text { Review/framework } & \text { Morkunas et al. } & 2019 \\ & & \text { Blockchain } & \text { Framework/literatur } & \text { Biswas and }\end{array}$

DEMATEL technique Strategic J Ł urcing: an International Journal e review, experts' Gupta,

Page 44 of 108 and experts' opinions

Ethereum

\section{blockchain-based} logistics monitoring

system (BLMS)

$-$

Hyperledger fabric

Blockchain Peer-to-peer

Peer-to-peer value exchange

systems, group consensus

mechanisms and smart

contracts

Business Model$$
-
$$

Blockchain

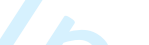

Review

Blockchain

Blockchain

Blockchain

Book

review/Literature

review

Blockchain-based distributed network architecture
Blockchain

Framework

Blockchain

Framework
Iansiti and

Lakhani

2017

Sharma et al.

2018

9

Helo and Hao,

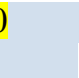




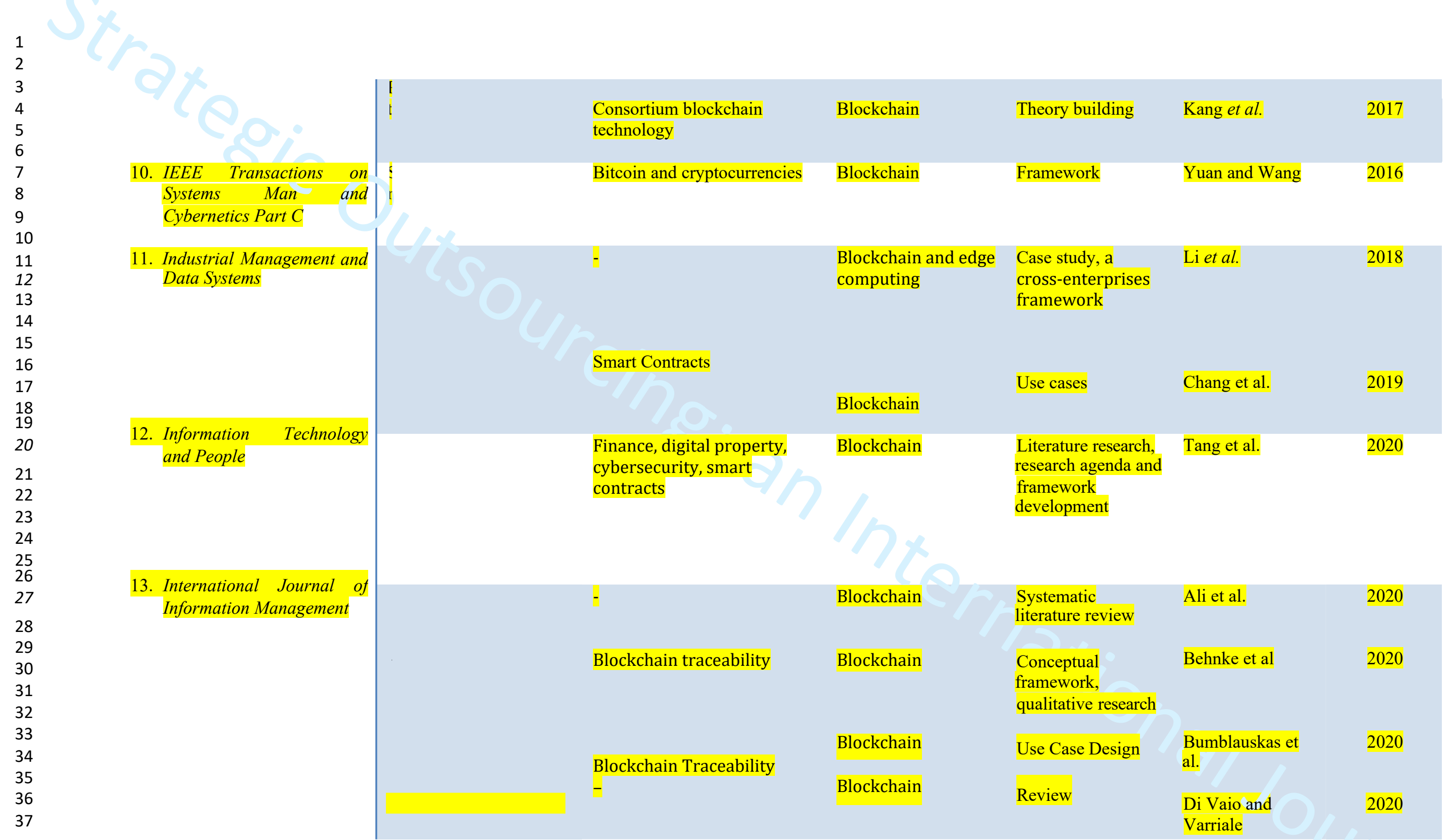




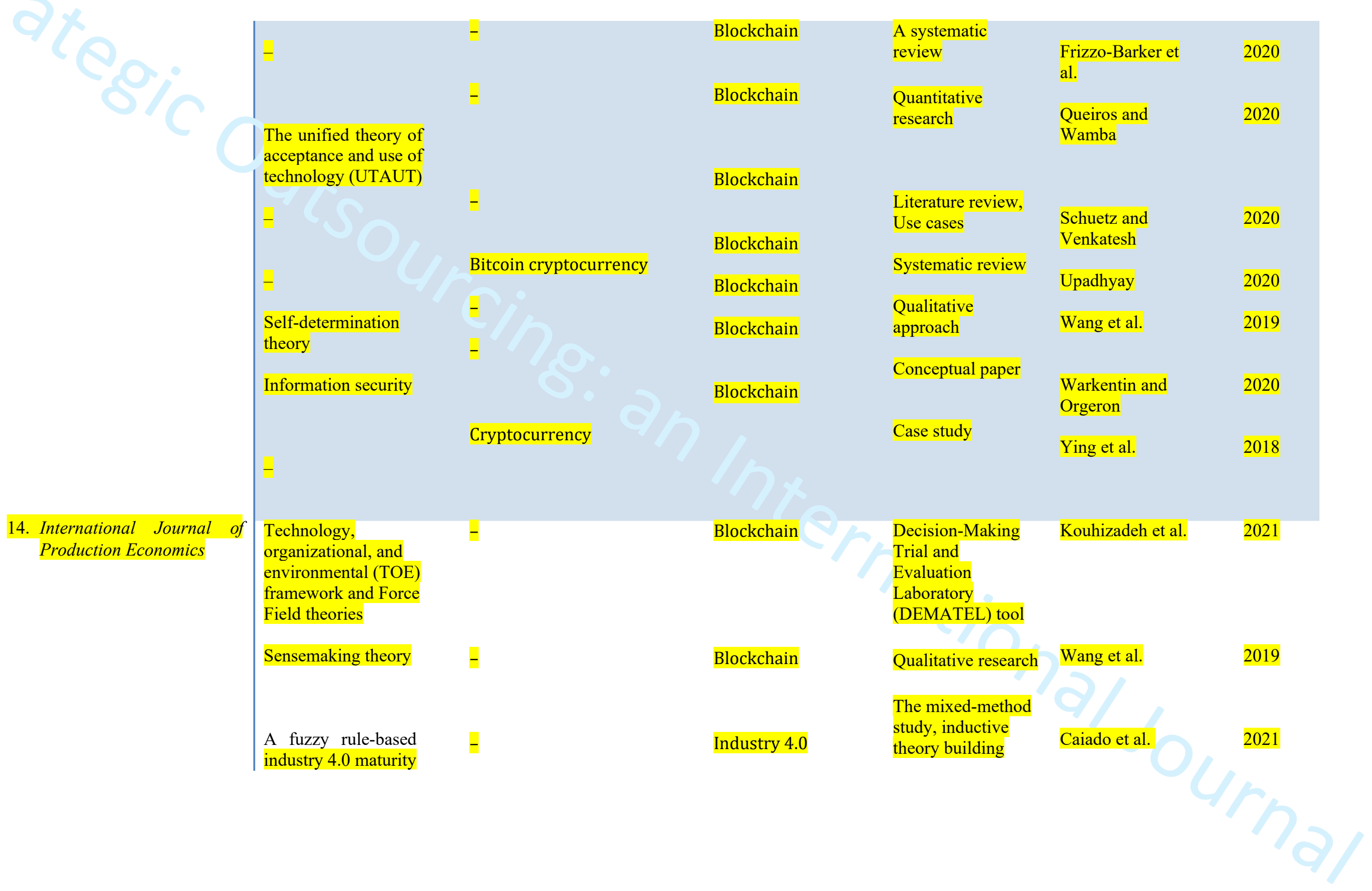


15. International Journal of Production Research

16. Intelligent Systems in Accounting, Finance and Management

17. Journal of Business Research

18. Journal of Business

\section{Blockchain \\ Quantitative \\ Kamble et al. \\ research \\ Kamble et al.}

Technology Acceptance

Model (TAM), Theory

of planned behaviour

(TPB), Technology

readiness index (TRI)

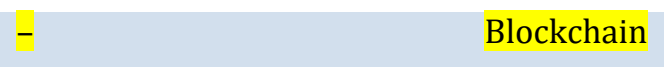

2019

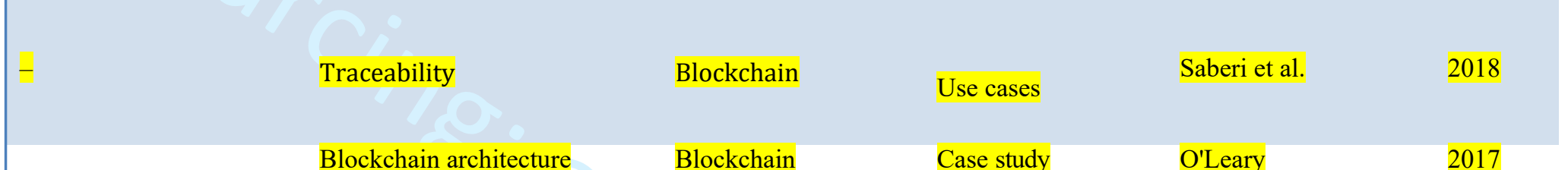

\begin{tabular}{|c|c|c|c|c|c|}
\hline & Blockchain architecture & Blockchain & Case study & O'Leary & 2017 \\
\hline - & $\begin{array}{l}\text { Blockchain traceability, smart } \\
\text { contract, Ethereum }\end{array}$ & Blockchain & Use cases & $\begin{array}{l}\text { Kim and } \\
\text { Laskowski }\end{array}$ & 2018 \\
\hline & Consortium Blockchain & Blockchain & Analysis study & O'Leary & 2018 \\
\hline - & Traceability of products & Internet of Things, & Use cases & Kumar et al. & 2020 \\
\hline & & $\begin{array}{l}\text { Artificial } \\
\text { Intelligence, Machine } \\
\text { Learning, and } \\
\text { Blockchain }\end{array}$ & & & \\
\hline & - & Blockchain, Additive & Inductive in-depth & Kurpjuweit et al & 2019 \\
\hline
\end{tabular}




\begin{tabular}{|c|c|c|c|c|c|c|}
\hline Logistics & & & manufacturing & $\begin{array}{l}\text { interviews with the } \\
\text { Delphi method }\end{array}$ & & \\
\hline $\begin{array}{l}\text { 19. Journal of Economics and } \\
\text { Business }\end{array}$ & Behavioural perspective & - & - & Use cases & Anagnostopoulos & 2018 \\
\hline $\begin{array}{l}\text { 20. Journal of Enterprise } \\
\text { Information Management }\end{array}$ & - & - & Blockchain & $\begin{array}{l}\text { Use cases, } \\
\text { Systematic } \\
\text { fit analysis/ } \\
\text { Descriptive } \\
\text { literature review }\end{array}$ & Siegfried et al & 2020 \\
\hline $\begin{array}{l}\text { 21. Journal of Financial } \\
\text { Economics }\end{array}$ & Game-theoretic model & Bitcoin blockchain & Blockchain & Use cases & Easley et al. & 2019 \\
\hline 22. Journal of Financial & & & & & & \\
\hline Regulation and Compliance & - & - & Blockchain & $\begin{array}{l}\text { Qualitative } \\
\text { research, case study }\end{array}$ & Yeoh & 2017 \\
\hline $\begin{array}{l}\text { 23. Journal of Management } \\
\text { Information Systems }\end{array}$ & - & Bitcoin Blockchain & Blockchain & Review & Yin et al. & 2018 \\
\hline 24. Journal of Manufacturing & & & & & & \\
\hline Technology Management & - & - & Industry 4.0 & $\begin{array}{l}\text { Conceptual } \\
\text { approach and } \\
\text { review }\end{array}$ & $\begin{array}{l}\text { Claudia Lizette } \\
\text { Garay-Rondero et } \\
\text { al. }\end{array}$ & 2019 \\
\hline $\begin{array}{l}\text { 25. International Journal of } \\
\text { Retail and Distribution } \\
\text { Management }\end{array}$ & - & - & New business models & Bibliometric study & Delafenestre & 2019 \\
\hline $\begin{array}{l}\text { 26. Journal of Service } \\
\text { Management }\end{array}$ & - & Smart contracts & Blockchain & Conceptual & De Keyser et al. & 2019 \\
\hline 27. Management Decision & $\begin{array}{l}\text { Sustainable business } \\
\text { model innovation }\end{array}$ & - & Blockchain & $\begin{array}{l}\text { Value Triangle } \\
\text { framework, case } \\
\text { study }\end{array}$ & Tiscini et al & 2020 \\
\hline
\end{tabular}




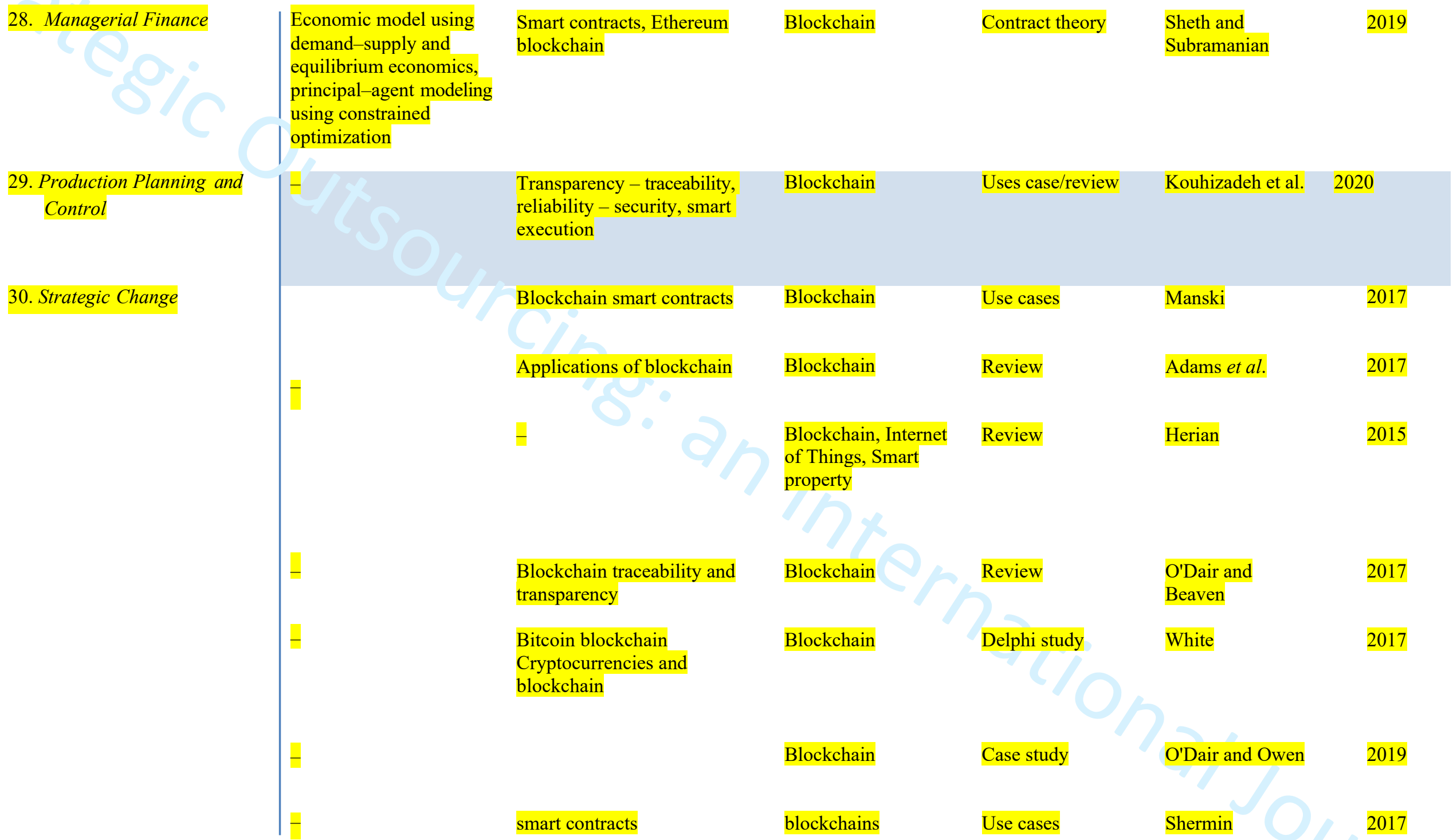


33. Technology Analysis and Strategic Management

34. Technological Forecasting and Social Change

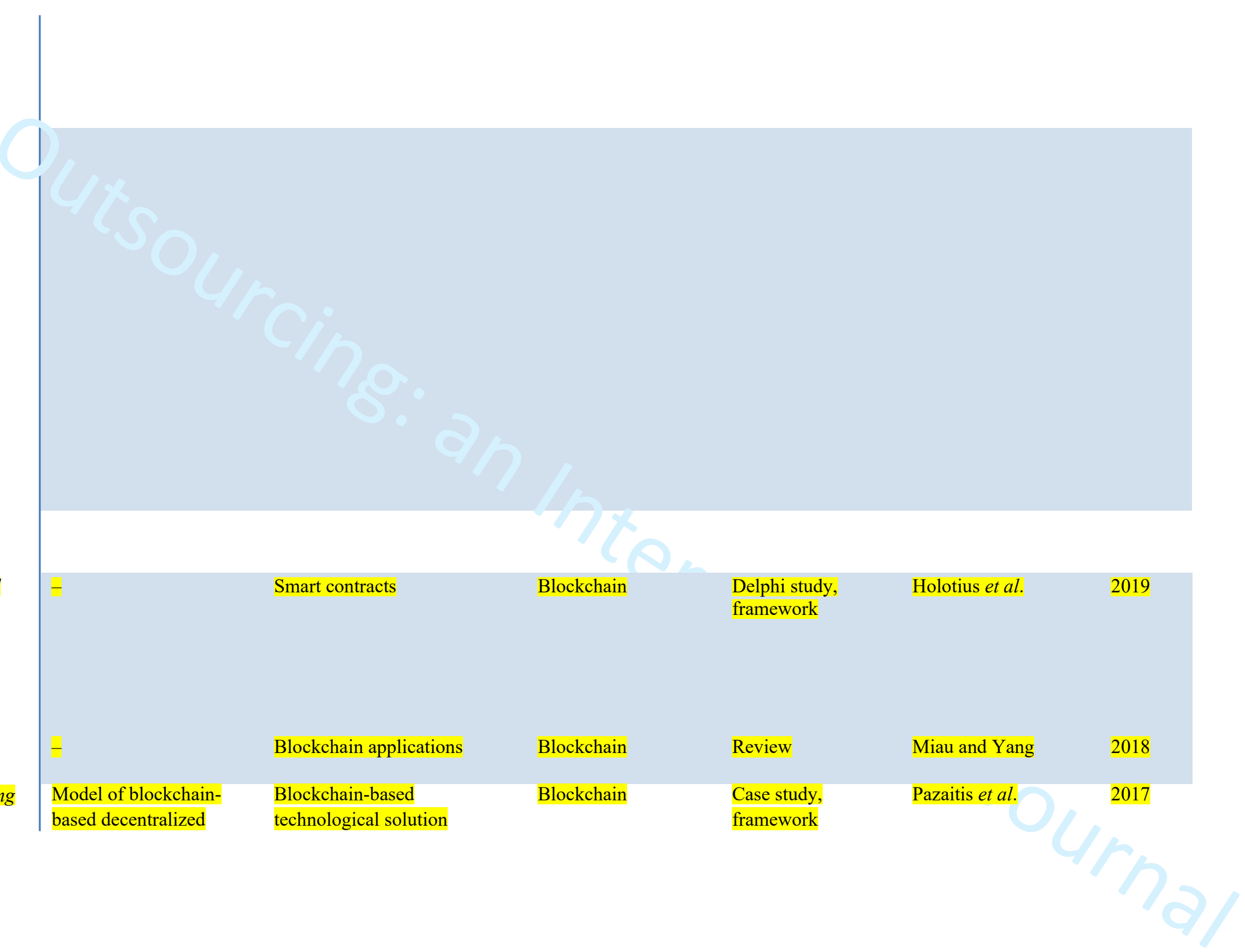


cooperation

- Blockchain Use cases Jianchao et al.

2020

Michael Porter five

forces model, SWOT

Analysis

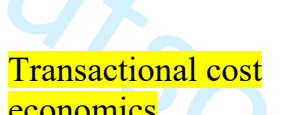

Blockchain

Use cases

Ahluwalia et al.

economics

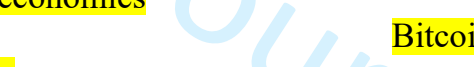

Bitcoin

Uses cases

White et al

Theory of Planned

Behavior (TPB)

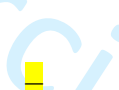

Blockchain

Qualitative method Chang et al.

$2020 \mathrm{a}$

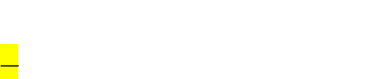

Blockchain

Experimental

Pólvora et al.

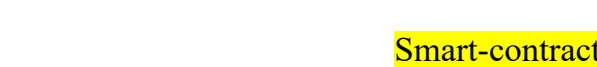

Blockchain

approach

Conceptual

framework

Chang et al.

$2019 b$

35. Transportation Research

Game theory

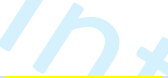

Conceptual

framework

\section{Blockchain}

?

Table 4. Findings and limitations of related studies: the categorisation of blockchain challenges and opportunities of blockchain 


\begin{tabular}{|c|c|c|c|c|c|c|c|c|}
\hline 1. & $\begin{array}{l}\text { Accounting and } \\
\text { Finance }\end{array}$ & Blockchain & 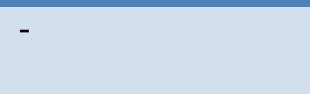 & $\begin{array}{l}\text { Financial } \\
\text { intermediation }\end{array}$ & FinTec & $\begin{array}{l}\text { Financial } \\
\text { Institution }\end{array}$ & Cai & 2018 \\
\hline 2. & $\begin{array}{l}\text { British } \quad \text { Food } \\
\text { Journal }\end{array}$ & Blockchain & - & $\begin{array}{l}\text { Traceability and } \\
\text { transparency }\end{array}$ & $\begin{array}{l}\text { Meat supply } \\
\text { chain }\end{array}$ & Meat industry & Sanders et al & 2018 \\
\hline \multirow[t]{2}{*}{3.} & \multirow[t]{2}{*}{ Business Horizons } & Blockchain & $\begin{array}{l}\text { Scalability, lack of } \\
\text { expertise, optimum } \\
\text { platform, } \\
\text { organisational } \\
\text { resistance, } \\
\text { computing } \\
\text { processing power }\end{array}$ & $\begin{array}{l}\text { Smart contracts, } \\
\text { cybersecurity, } \\
\text { asset tracking }\end{array}$ & $\begin{array}{l}\text { Supply chain } \\
\text { resilience }\end{array}$ & - & Min & 2019 \\
\hline & & $\begin{array}{l}\text { Public and private } \\
\text { blockchain }\end{array}$ & $\begin{array}{l}\text { Blockchain is slow } \\
\text { in operation, Data } \\
\text { breaches of } \\
\text { cryptocurrency } \\
\text { trading platforms, } \\
\text { Blockchain systems } \\
\text { are not } \\
\text { standardised, } \\
\text { blockchain } \\
\text { architectures is } \\
\text { difficult, lack of a } \\
\text { critical mass of } \\
\text { users }\end{array}$ & $\begin{array}{l}\text { New Consensus } \\
\text { Mechanisms used } \\
\text { for Hyperledger }\end{array}$ & $\begin{array}{l}\text { Firm's } \\
\text { business } \\
\text { model }\end{array}$ & - & Morkunas et al. & \\
\hline 4. & $\begin{array}{l}\text { Computers and } \\
\text { Industrial } \\
\text { Engineering }\end{array}$ & Blockchain & $\begin{array}{l}\text { Scalability and } \\
\text { market-based risks, } \\
\text { Transactional-level }\end{array}$ & - & $\begin{array}{l}\text { Barriers to the } \\
\text { adoption and } \\
\text { implementatio } \\
\mathrm{n} \text { of }\end{array}$ & $\begin{array}{l}\text { Industry and } \\
\text { service sector }\end{array}$ & $\begin{array}{l}\text { Biswas and } \\
\text { Gupta, }\end{array}$ & 2019 \\
\hline
\end{tabular}


uncertainties,

blockchains

Technology risks,

High sustainability

costs, Poor

economic

behaviour, in the

long run, Privacy

risks, Usages in the

underground

economy, Risk of

cyber-attacks, Legal

and regulatory

uncertainties

Helo and Hao

\section{Blockchain}

5. Decision Sciences Journal

6. Energy Policy

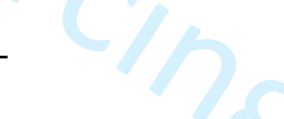

\section{Tamper-proof \\ transaction \\ records, \\ Information \\ sharing \& \\ synchronization, \\ Smart contract \\ execution,}

Blockchain

Blockchain
Operations

and supply

chain

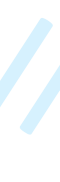


7. Foresight

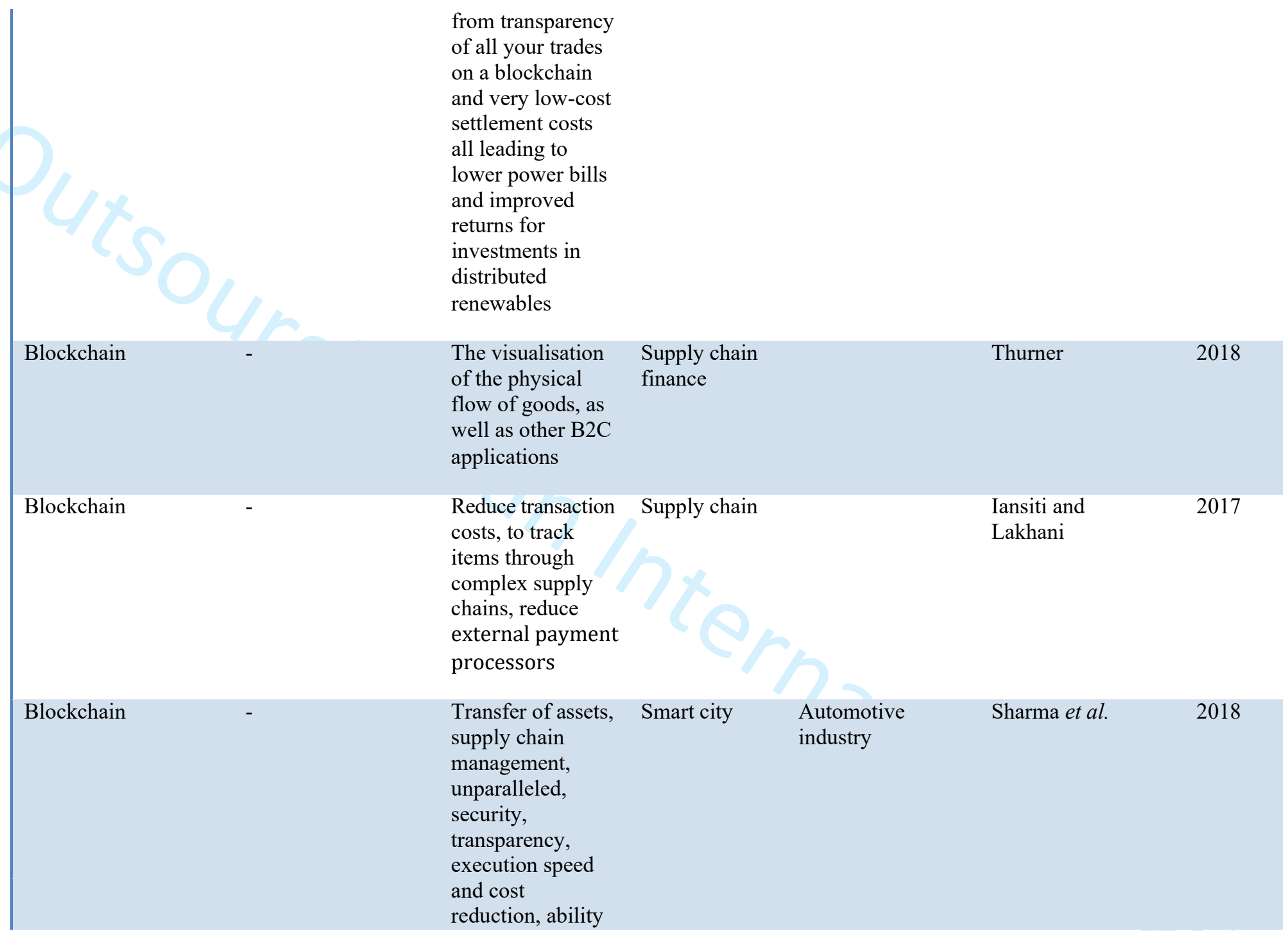


10. IEEE Transactions on Systems Manand Cybernetics Part $C$

11. Industrial Management and Data Systems to audit records,

System

initialization and

key generation,

choosing different

roles in electricity

trading,

selling and buying

energy,

paying and

earning energy

coins,

carrying Out

consensus

process, building

Blocks and

Finding Proof-of-

Work

\section{Localise buy Automotive Kang et al.}

and selling industry

electricity

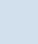

Kang et al. 


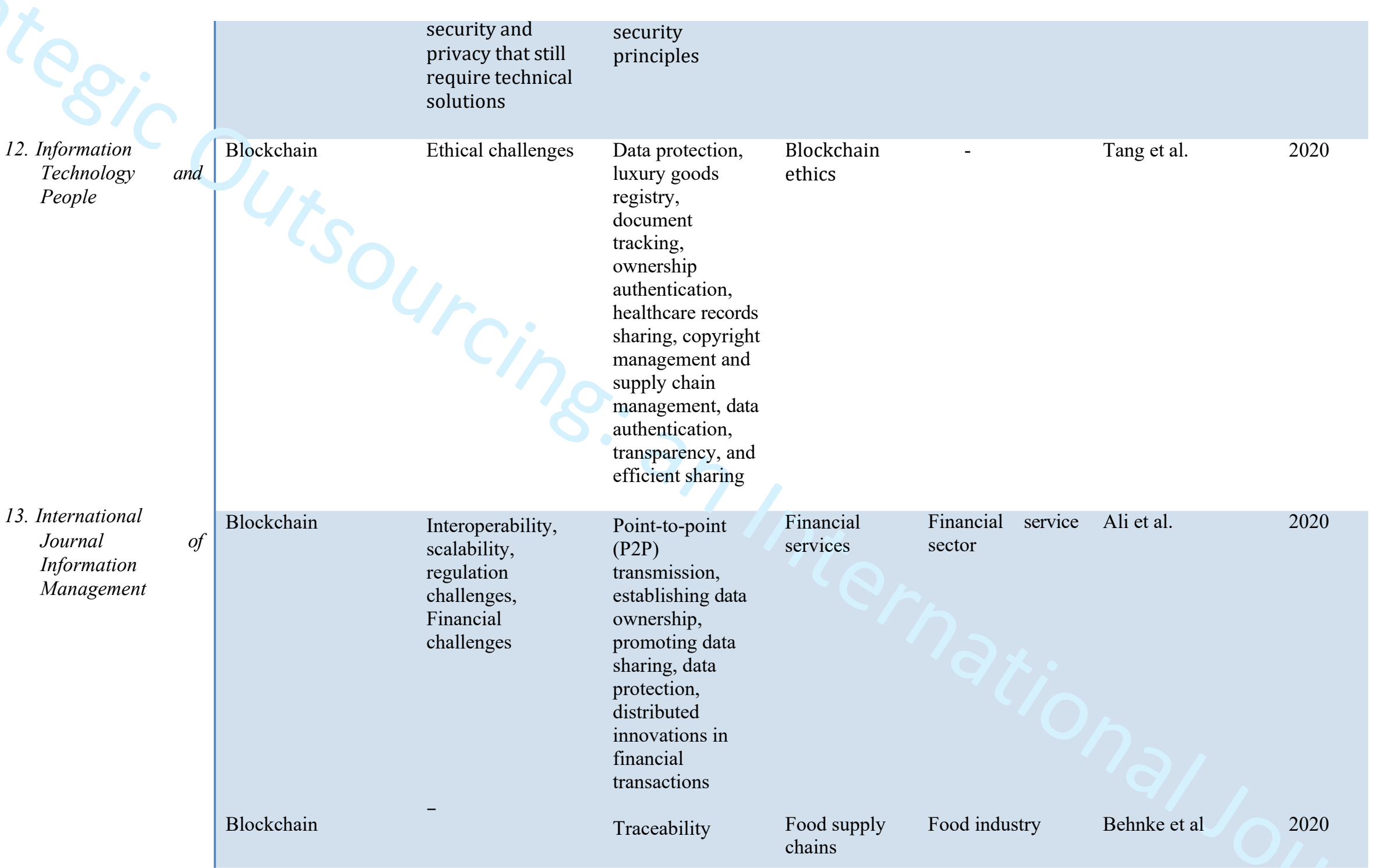




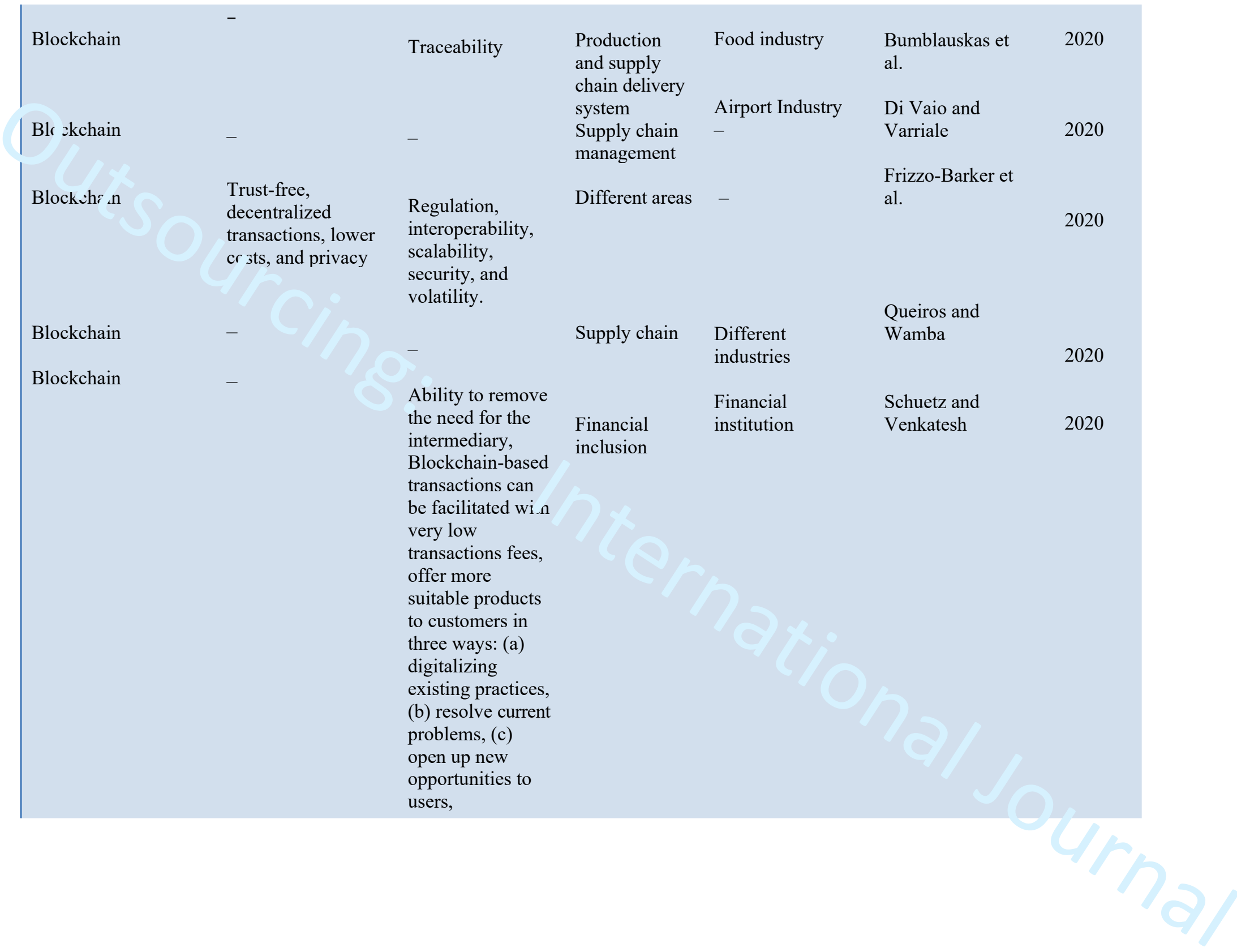




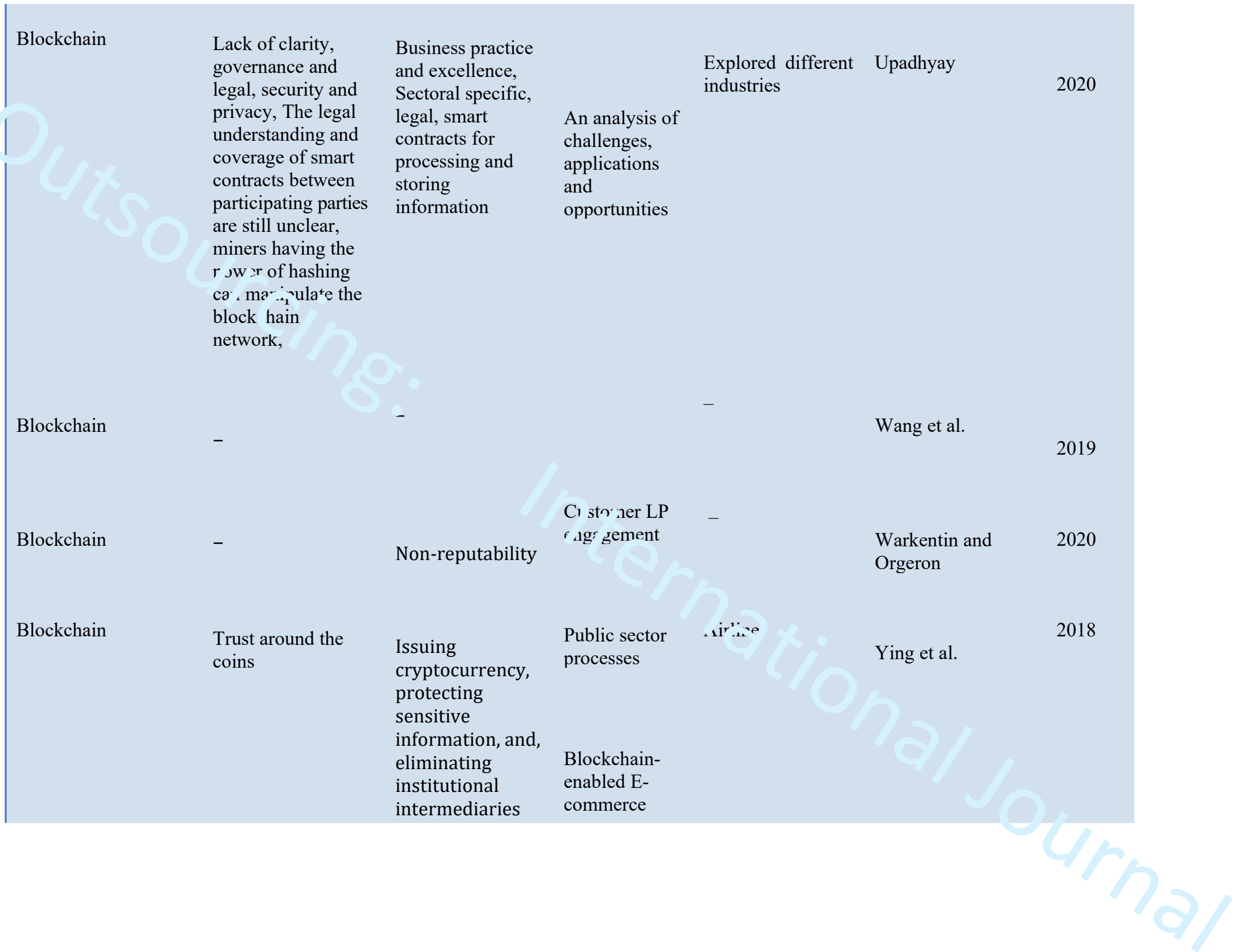


14. International Journal

Production

Economics

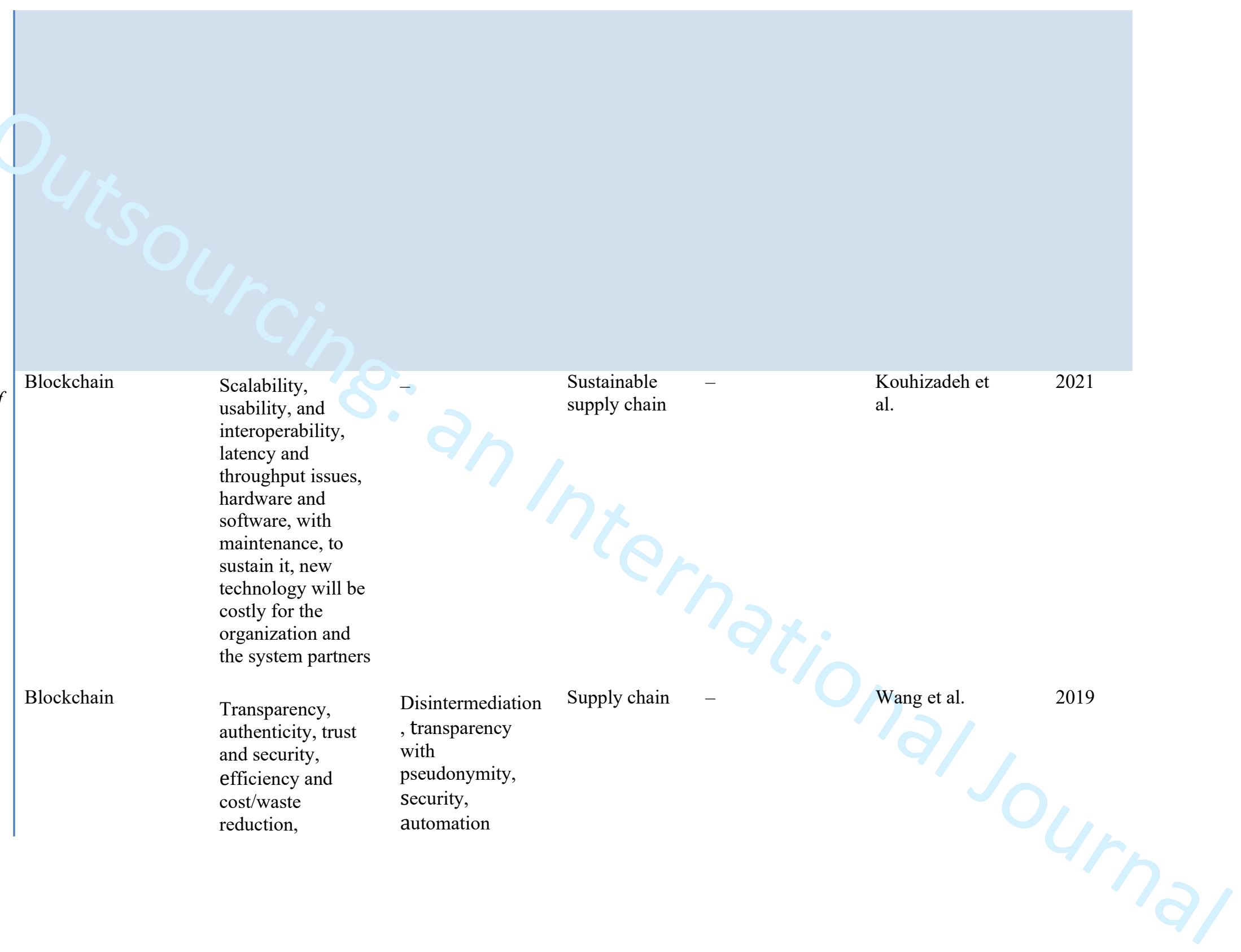




\section{International} Journal

Production Research
Blockchain

"51\% attack",

technical know-

how, data

governance and

privacy-related

concerns

management

Opportunity to
create numerous
sharing
applications, e.g.
peer-to-peer
automatic
payment
mechanisms,
foreign exchange
platforms, digital
rights
management and
cultural heritage

Blockchain

$\begin{array}{ll}\text { Different privacy } & \text { Tracking } \\ \text { policies, data usage, } & \text { substandard } \\ \text { new IT tools are } & \text { products } \\ \text { needed, 'bloat' } & \text { accurately, } \\ \text { problem in Bitcoin, } & \text { identification of } \\ \text { Data security and } & \text { transactions of } \\ \text { privacy concerns, } & \text { the products to } \\ & \text { reduce the rework } \\ & \text { and recall, to } \\ & \text { ensure that } \\ & \text { purportedly green } \\ & \text { products are } \\ & \text { environmentally } \\ & \text { friendly, reduce } \\ & \text { carbon emissions } \\ & \text { in the journey of }\end{array}$

Supply chains

Kamble et al.

2019

Sustainable

supply chain 
16. Intelligent Systems in Accounting,
Finance and Management products by

providing the

fundamentals for

supply chain

mapping and

applying low-

carbon product

design, improve

the recycling,

emission trading

process by

improving

emission trading

schemes (ETS)

efficacy

Disintermediation

Accounting

O’Leary,

2017

\section{Blockchain}

Open networ
designs,

of financial

and supply

intermediaries,

chain systems

payment

networks, stock

exchanges and

money transfer

services, provides

each participant

end-to-end

visibility,

traceability.

Blockchain

Interoperability

$p$

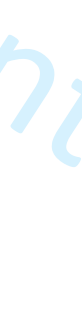

Supply-chain
provenance
Traceability
Kim and Laskowski 


\begin{tabular}{|c|c|c|c|c|c|c|c|}
\hline & Blockchain & $\begin{array}{l}\text { Spoofing, wash, } \\
\text { and off-blockchain } \\
\text { transactions at } \\
\text { Bitcoin: business } \\
\text { manipulation, } \\
\text { spoofing wash } \\
\text { accounts, and off- } \\
\text { blockchain } \\
\text { accounting and } \\
\text { supply chain, } \\
\text { Crime and } \\
\text { Information } \\
\text { Disclosures in } \\
\text { Bitcoin or } \\
\text { Peer-to-Peer } \\
\text { Systems. }\end{array}$ & $\begin{array}{l}\text { Peer-to-Peer } \\
\text { Public } \\
\text { Blockchain, } \\
\text { smart contracts }\end{array}$ & $\begin{array}{l}\text { Open } \\
\text { information } \\
\text { transactions }\end{array}$ & - & O'Leary & 2018 \\
\hline $\begin{array}{l}\text { 17. Journal of Business } \\
\text { Research }\end{array}$ & Blockchain & $\begin{array}{l}\text { Technological } \\
\text { expertise }\end{array}$ & $\begin{array}{l}\text { Disintermediation } \\
\text { and direct } \\
\text { engagement, } \\
\text { Customer } \\
\text { outcomes, } \\
\text { Personalization of } \\
\text { marketing mix } \\
\text { elements, better } \\
\text { prediction of } \\
\text { future trends, } \\
\text { productivity } \\
\text { enhancement, } \\
\text { enhanced } \\
\text { functional ease, } \\
\text { Greater personal } \\
\text { relevance, } \\
\text { Greater } \\
\text { traceability of } \\
\text { products, }\end{array}$ & Marketing & - & Kumar et al. & 2020 \\
\hline
\end{tabular}


20

21

22

24

25

26

27

28

29

30

31

32

33

34

35

36

37

38

39

40

41

42

43

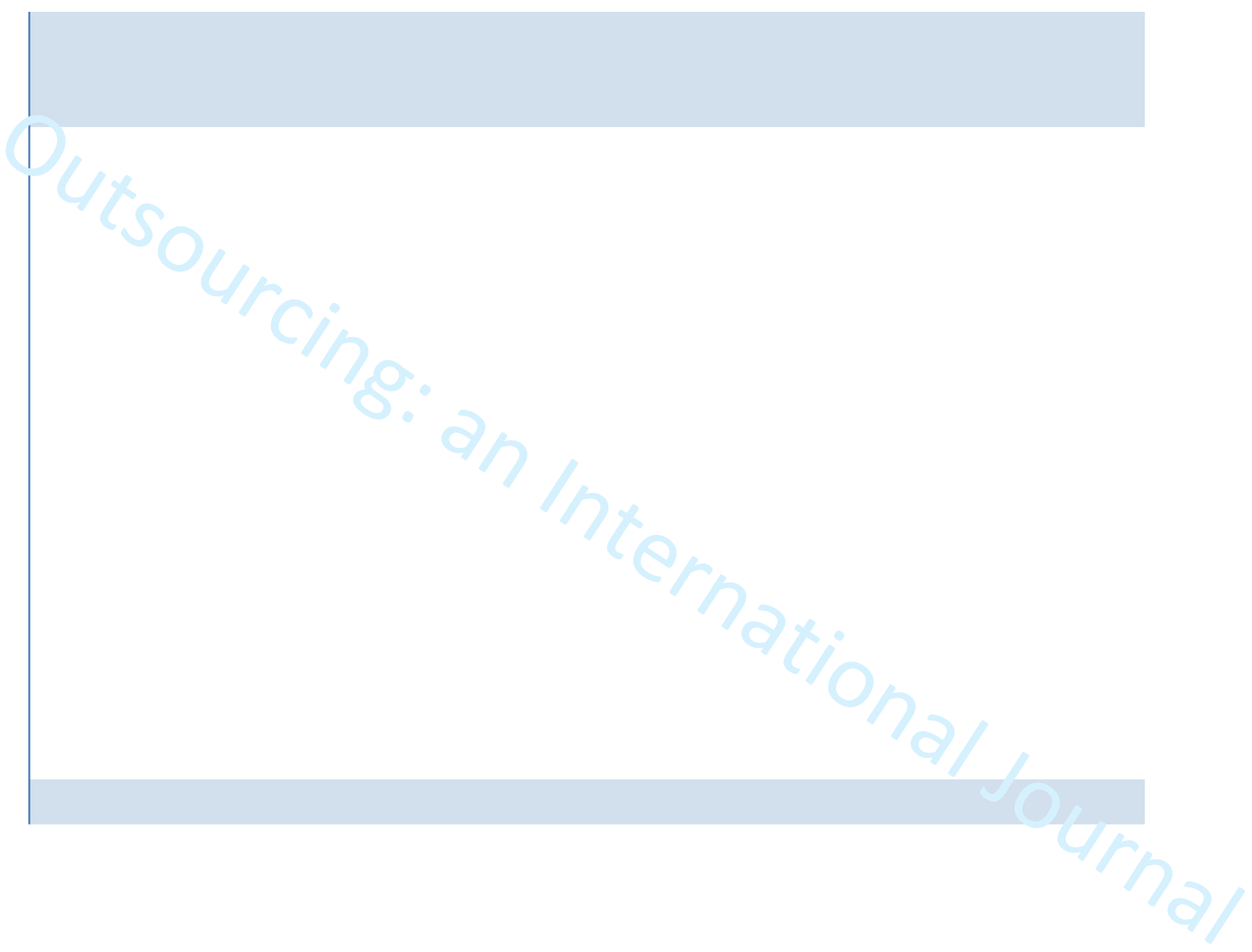




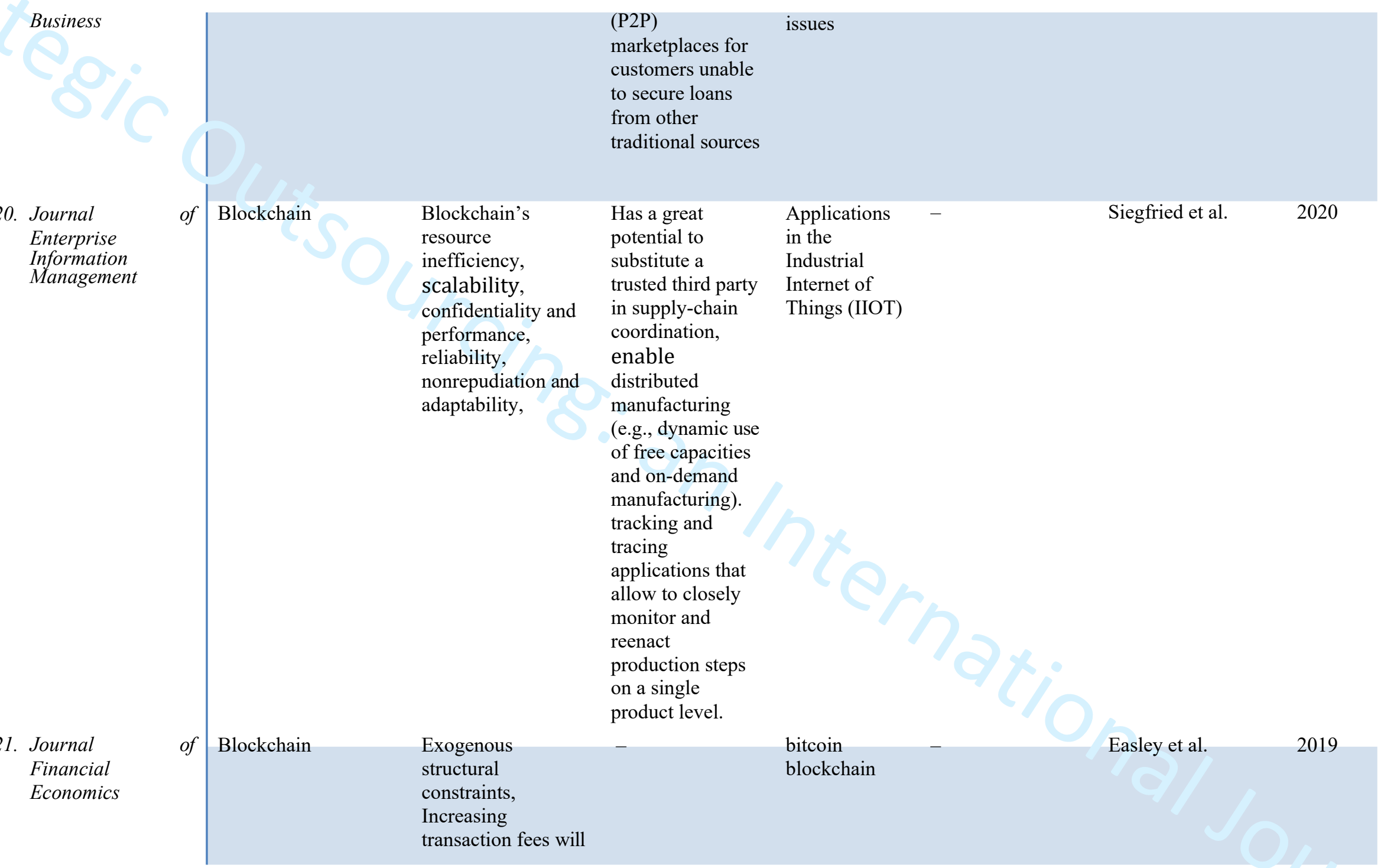


22. Journal of Regulation and Compliance

23. Journal of Management

Information

Systems

24. Journal of Manufacturing

Technology

Management

25. International Journal of Retail and Distribution Management increase the number

of miners, but this,

in turn, will trigger

increases in the

difficulty level to

control the creation

rate of new blocks,

thereby raising the

costs to miners,

Transactions and

the mempool,

Waiting times and

transaction fees.

$\begin{array}{llllll}\text { Blockchain } & \text { Regulatory issue, } & - & \begin{array}{l}\text { Regulatory } \\ \text { issues }\end{array} & \text { Financial Services } & \text { Yeoh }\end{array}$

\begin{tabular}{|c|c|c|c|}
\hline Blockchain & $\begin{array}{l}\text { Legal and } \\
\text { Regulatory } \\
\text { Perspective, } \\
\text { Anonymity } \\
\text { Perspective }\end{array}$ & - & $\begin{array}{l}\text { Regulating } \\
\text { Cryptocurrenc } \\
\text { ies }\end{array}$ \\
\hline Industry 4.0 & Interoperability & - & $\begin{array}{l}\text { Digital Supply } \\
\text { Chains } \\
\text { (DSCs) }\end{array}$ \\
\hline New business models & - & $\begin{array}{l}\text { New business } \\
\text { model }\end{array}$ & Supply chains \\
\hline
\end{tabular}


26. Journal of Service Management

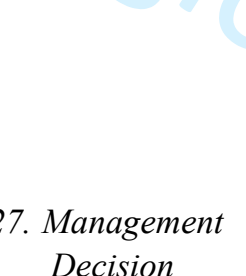

Decision

\begin{tabular}{|c|c|c|c|c|c|c|}
\hline $\begin{array}{l}\text { Frontline Service } \\
\text { Technology infusion }\end{array}$ & - & $\begin{array}{l}\text { Smart contracts, } \\
\text { new business } \\
\text { models, removal } \\
\text { of traditional } \\
\text { third-party service } \\
\text { intermediaries }\end{array}$ & $\begin{array}{l}\text { Conversationa } \\
1 \text { agents, } \\
\text { extended } \\
\text { reality (XR) } \\
\text { and } \\
\text { blockchain } \\
\text { technology }\end{array}$ & - & De Keyser et al. & 2019 \\
\hline Blockchain & $\begin{array}{l}\text { Scalability, } \\
\text { Technical essential } \\
\text { facilities, } \\
\text { sophisticated ICTs } \\
\text { are needed }\end{array}$ & $\begin{array}{l}\text { Information about } \\
\text { quality (e.g. } \\
\text { geographic } \\
\text { origins and } \\
\text { freshness), safety } \\
\text { (e.g. healthiness } \\
\text { and no } \\
\text { modification) and } \\
\text { sustainability (e.g. } \\
\text { fair-trade) of the } \\
\text { products are } \\
\text { guaranteed and } \\
\text { ensures data } \\
\text { transparency, } \\
\text { integrity and } \\
\text { security, } \\
\text { eliminates the } \\
\text { waste of safe } \\
\text { food, being able } \\
\text { to promptly locate } \\
\text { and trace } \\
\text { contaminated } \\
\text { products, allow } \\
\text { agri-food } \\
\text { companies to } \\
\text { reduce natural } \\
\text { resources }\end{array}$ & $\begin{array}{l}\text { Sustainable } \\
\text { business } \\
\text { model } \\
\text { innovation }\end{array}$ & $\begin{array}{l}\text { Agric- } \quad \text { food } \\
\text { industry }\end{array}$ & 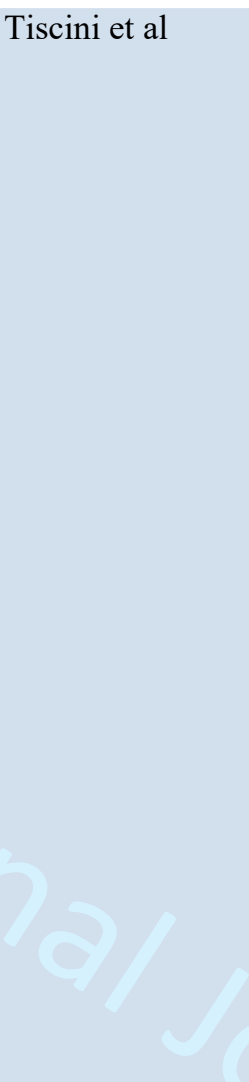 & 2020 \\
\hline
\end{tabular}




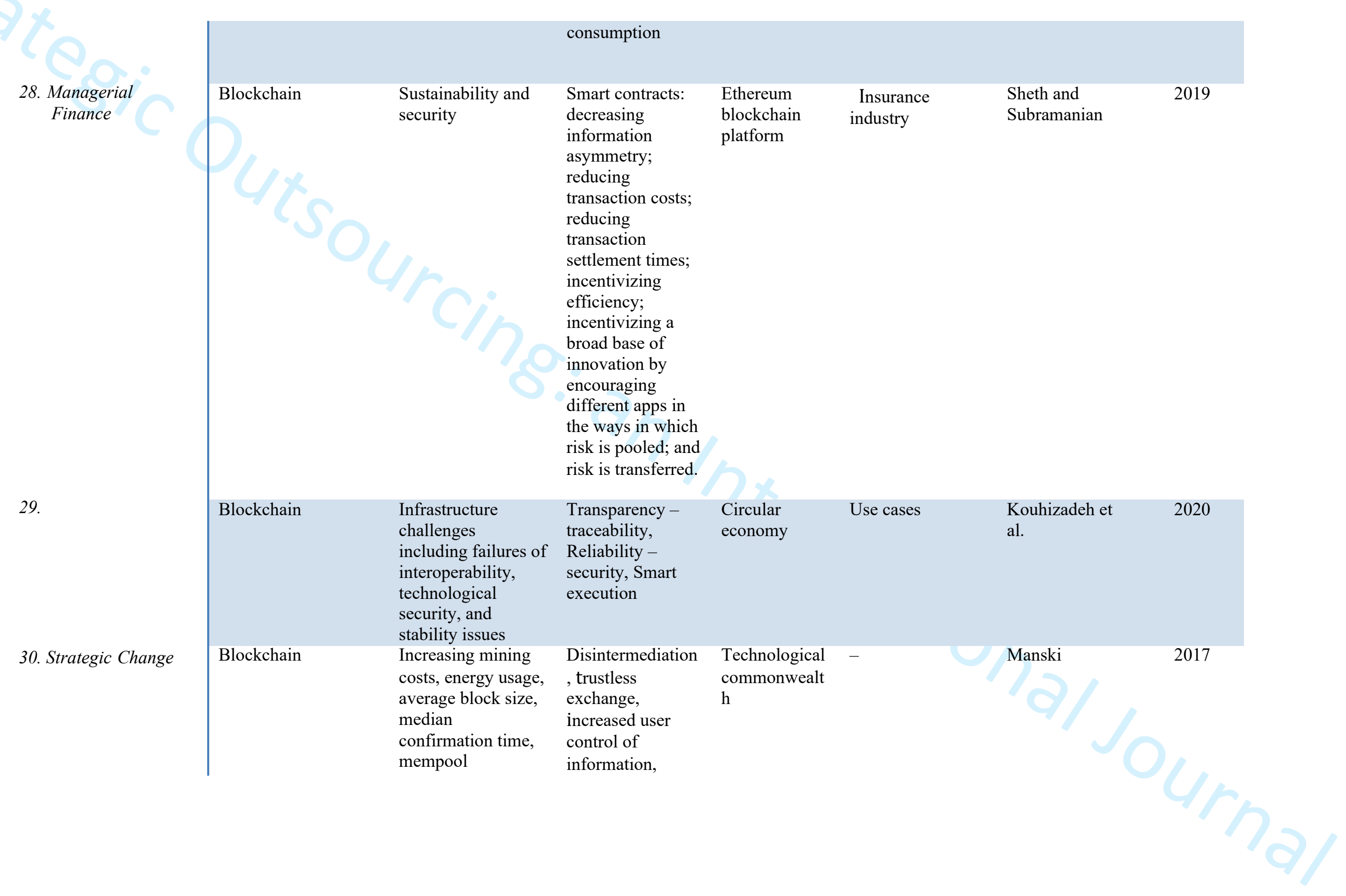


transaction count, and user fees,

limited

user-friendliness

and superior

technical expertise

required are acting

as barriers to

adoption, Unsettled

regulatory

environment durable, secure

decentralized

networks,

transparency and

immutability,

maintenance of

high-quality,

accurate data

Blockchain

Blockchain

Underlying

cryptocurrencies,

from the legal and

regulatory to the

ethical and

environmental, the

issue of suspicion

based on the strong

association of

Accuracy and

availability of

copyright data,

facilitate

near-instant

micropayments

for royalties,

improve the

transparency of

\section{Future of}

Adams et al.

money

\section{(re)imagining}

of trusts

Herian

jurisprudence

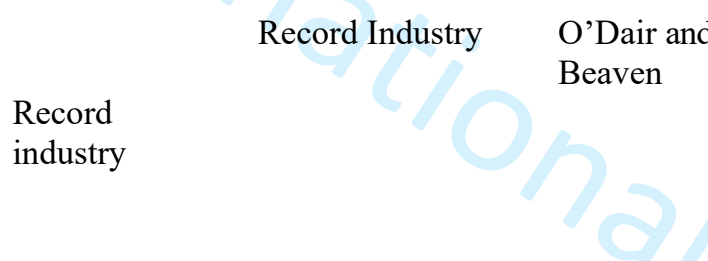


blockchain

the value chain.

technology with

Bitcoin, associated

with "dark web"

sites such as Silk

Road, governance

and regulation, the

integrity of the data,

Blockchain

Security concerns,

technical

Transfer of bonds,

White

limitations, growth

and sustainability,

and environmental

payment of

medical bills,

Business and

impact.

register of

management

electronic voting,

recording

personal, transfer

Blockchain

of bonds,

new creative
enterprise

Blockchain

Scalability, the

speed of the

network, or lack

thereof

enterprise

Music Industry

O’Dair and

Reduce

New creative

transaction costs

of reaching an

agreement,

formalization and

enforcement of

relationships

between people,

institutions, and

the assets they

own, by

standardizing

Shermin

Disrupting governance 
transaction rules,

create novel

opportunities for

economic

alignment, shared

purpose, and

coordination

between

distributed

trustless

individuals, at

negligible cost,

decentralized

virtual borderless

nations.

Blockchain

Bitcoin as a

currency is that it is

Greater security

rarely used by

transparency,

vendors within the auditability, and

Distributed

"real economy" as a efficiency to

collaborative

means of exchange,

currency

organizations

its perception as a

"risky" currency.

31. Supply Chain

Management:

International

Journal

B

\section{Blockchain}

\section{Smart}

contracts will

contribute to

several SCM

improvements

such as

improved

responsiveness,

lead-time 


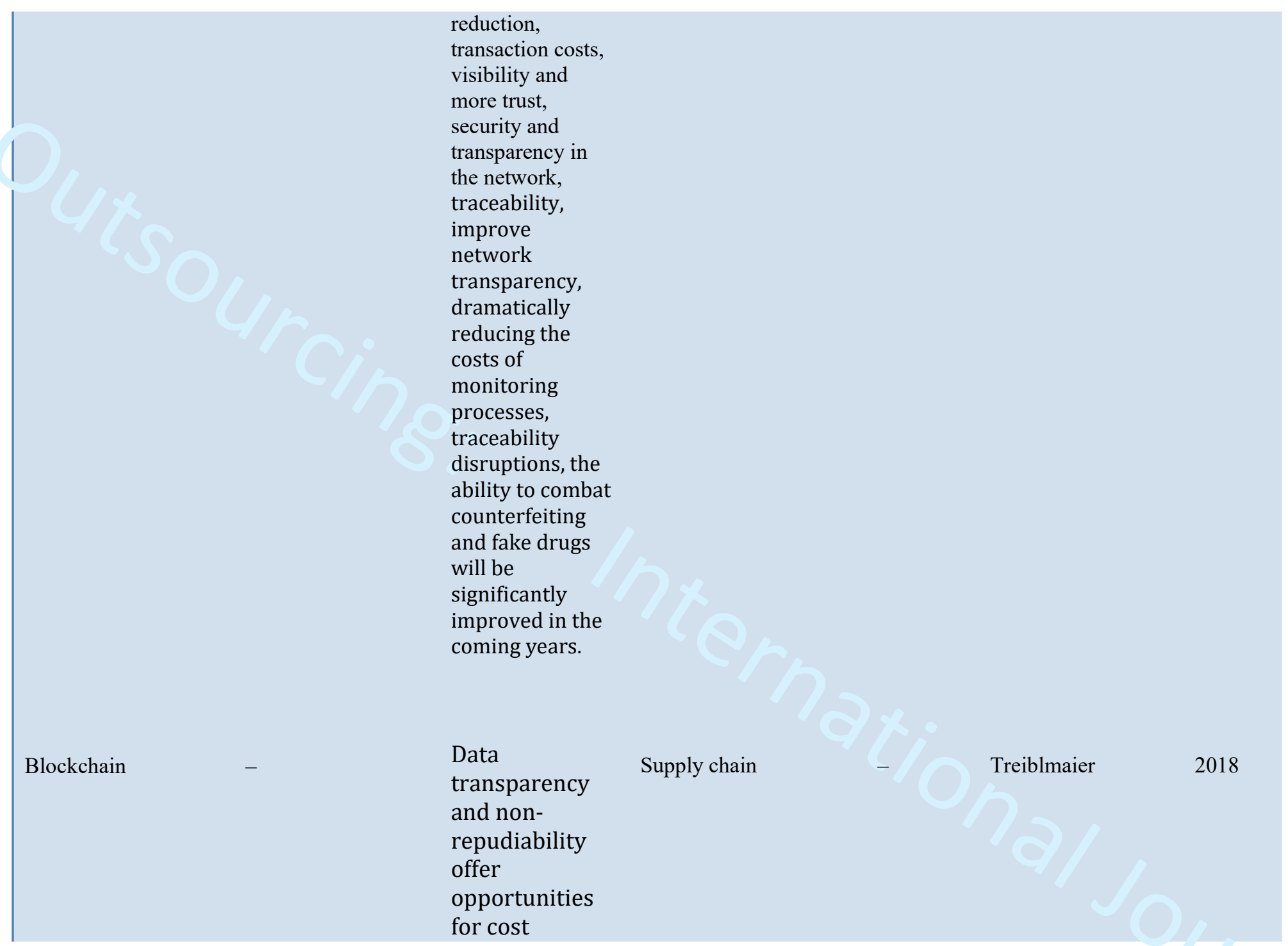




\author{
reduction and \\ independence \\ from the \\ services of \\ intermediaries, \\ new business \\ models,
}

\title{
Extended
}

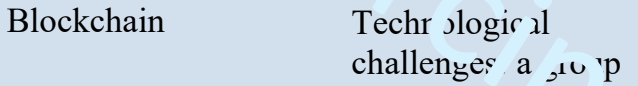

of miners

visibility and

product

Supply chains

Wang et al.

temporarily contr. 1

over 50 per

traceability,

cent of the

phly chain

digitalisation

and

network's mining

hash-rate, latency;

operational

disintermediati

on, Improved

data security

challenges: For a

blockchain to

work in the

for information

supply chain, all

related supply

chain actors

sharing, smart

contracts,

should be on

board

\section{Enhancing}

Blockchain Building human

product safety and

security;

capital expertise to

improving quality

Operations

and supply 
32. Systems Research and Behavioral

Science

33. Technology Analysis and Strategic Management

\section{develop,}

implement, and

exploit applications

of

redugement;

chain

ing illegal

management

improving

sustainable

supply chain

management;

advancing

inventory

management and

replenishment;

reducing the need

for intermediaries;

impacting new

product design

and development;

and reducing the

cost of supply

chain transactions

\begin{tabular}{|c|c|c|c|c|c|}
\hline- & $\begin{array}{l}\text { Problems of } \\
\text { financial regulation, } \\
\text { complexity in } \\
\text { global } \\
\text { collaboration, }\end{array}$ & Cybersecurity & $\begin{array}{l}\text { Finance and } \\
\text { er sn. nics }\end{array}$ & Zhang et al. & 2020 \\
\hline Blockchain & $\begin{array}{l}\text { Integration and } \\
\text { adoption, } \\
\text { standardisation, } \\
\text { unification, and } \\
\text { interoperability, } \\
\text { latency and } \\
\text { response time, } \\
\text { availability and } \\
\text { robustness, }\end{array}$ & $\begin{array}{l}\text { P2P and direct } \\
\text { transactions, } \\
\text { cross-border and } \\
\text { cross-currency, } \\
\text { a connection } \\
\text { between } \\
\text { contract and } \\
\text { transaction, cost } \\
\text { reduction, new }\end{array}$ & $\therefore$ arme t Ir dustry & Holotius et al. & 2019 \\
\hline
\end{tabular}


34. Technological Forecasting and models in
payments,

changed income

structure,

$-$

Miau and Yang

Blockchain

Blockchain

The legal and

regulatory,

Optimization of

measurement

and certification,

Insufficient

computing

power and

response speed,

Fault tolerance

challenge, The

lack of

responsible

parties in smart
To efficiently

allocate their

resources in a

more fair and

sustainable

fashion

value systems

in the sharing

economy

Pazaitis et al.

2017

Competitiveness

of distributed

Competitivene Energy Industry

Jianchao et al.

2020

energy

ss of

Construction of

distributed

market

energy

transactions,

Development of

energy finance

$r^{2}$


contracts

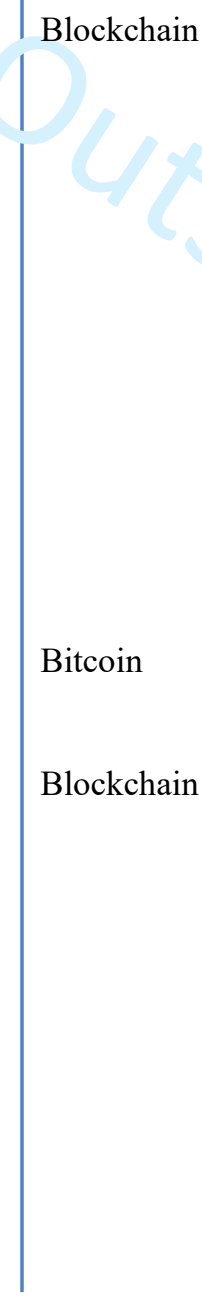
Blockchain
reduce
opportunism
verifiable smart,
blockchain
reduces
uncertainty by
completing
transactions
quickly without
the need of the
third party.

Startup

financing

Ahluwalia et al.

2020

Technology-
based product

Ethical issue:

privacy,

regulations and

law, cybercrime;

scalability,

security, privacy

leakage, energy

consumption:

changed the ways

that employees

work and

communicate
Optimization of
global financial
infrastructure or
transfer assets
more effectively
than the existing
financial system,
it reduces costs
and value
transfers, it can
control risks more
effectively, it
seeks innovative

Financial

Financial Industry Chang et al.

services 


\section{within the}

organization,

ways to profit

employees are

required to learn

new skills and

knowledge,

difficult to get

professional help,

"experts" are still

learning new

knowledge

themselves, not all

the organizations

have been entirely

ready for the

Blockchain

adoption

Blockchain

Interoperability,

New business and

fragmentation of

conomic mode

frameworks

trust and

Industrial

Pólvora

across Member

States, legal

recognition,

ns

acceptance or

governance,

guidance

concerning

Blockchain

solutions or

mechanisms,

such as

electronic

signatures,

or data

management.

?

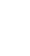


creation of

tokens or coins,

transactions

performed via

smart contracts,

management of

personal data, or

decentralized

governance

models 35. Transportation Emechnologies

Fast payment,

legal issues, lack $\begin{gathered}\text { Fast payment, } \\ \text { traceability, }\end{gathered}$

of standards and disintermediation

protocols,

disintermediation
of the service

privacy issues, third provider

and error

intolerance

Supply chain
re-engineering

Chang

$2019 b$

Scalability, the

monetization of

users mobility

Improve various

aspects in the

current way of

Smart

mobility data-

López and

information,

sharing and

collecting

mobility data,

Source: Designed by the authors 


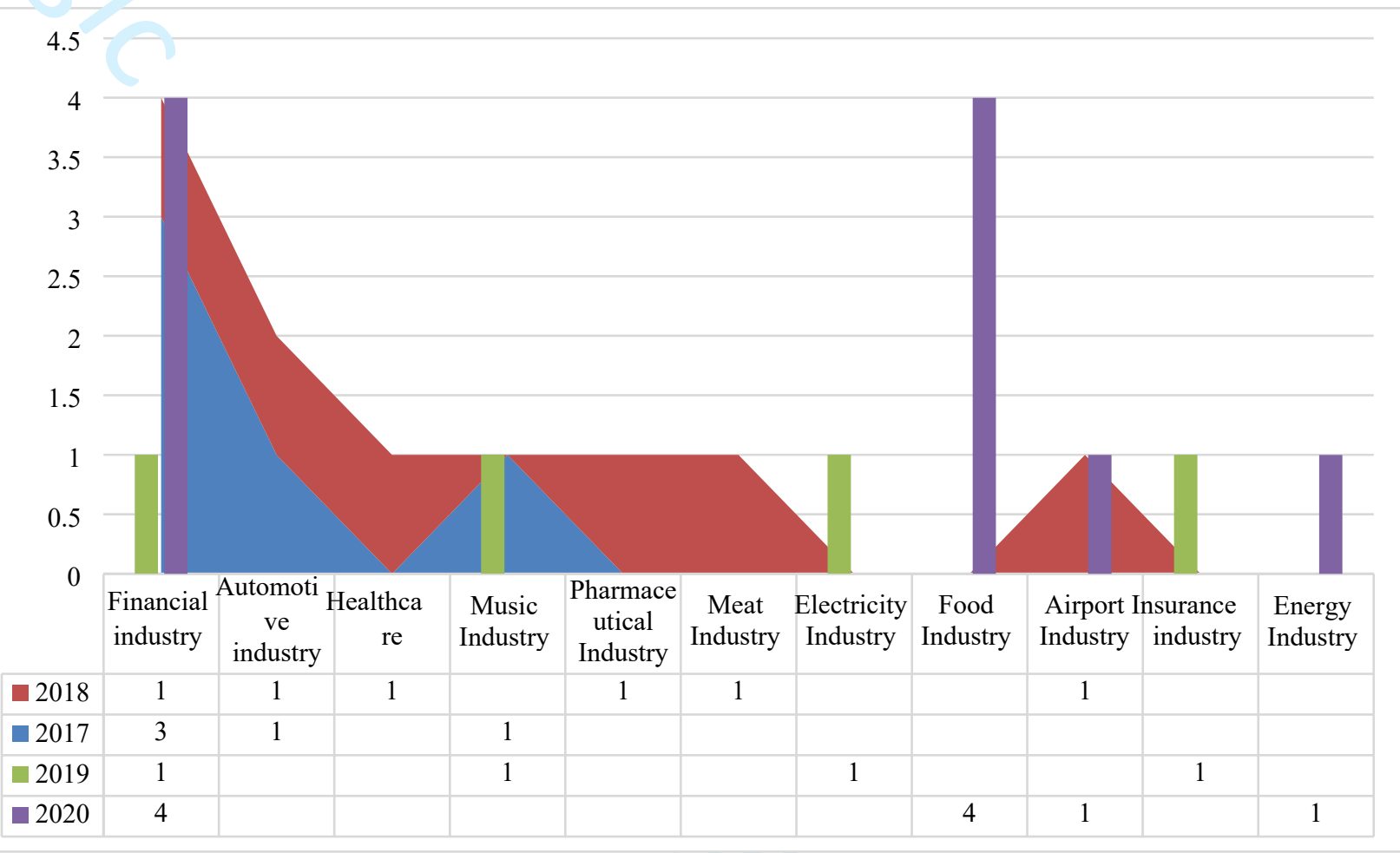

Figure 5 Categorisation of blockchain application articles found in different industries (Source: Designed by the authors)

Figure 5 shows that research studies on the blockchain in the financial industry received a lot of attention in the present research, which is related to the findings of Frizzo-Barker et al. (2020) conducted recently. Their systematic literature review study showed the bank sector received more attention compared to other industries. Based on the exploration of understanding blockchain technological and management challenges and opportunities for operational excellence, the literature review highlights various blockchain technological and management challenges and opportunities. This is shown from the sample of 69 articles in the present study in which only 5 articles were used to discuss blockchain management opportunities, 10 articles were used to discuss blockchain technological challenges, 24 articles were used to discuss blockchain management challenges, while 13 articles were used to discuss blockchain technological opportunities and 16 articles were used to discuss blockchain technology. 
Furthermore, studies that focused on the specific industry in Figure 5, differ from one industry to another and issues they focused differ from one to another. For example, in the financial industry, a literature review conducted by Cai, (2018) explored two major innovations such as blockchain and crowdfunding, and they argued it will provide further insight and understanding into a coming FinTec revolution. They argued that since the basic structure of technology allows individual to reach a general agreement in a decentralised manner will break the existing system of needing trusted centralised service providers to determine the authenticity of a transaction, as this has traditionally often been a major role of banks (traditional financial intermediaries. This may affect the operational excellence of the banks.

\section{Research Gap}

Research on blockchain adoption from ine lens of TOE framework for operational excellence has not received much attention (Cui et al. $2 l^{\prime} ?$ ') ) th provide a clear understanding of technological and management challenges and opportun i+ies of blockchain adoption. Although there is a study that asked the future research questionss at sut "how blockchain can be used in a better way to receive operational excellence?” (Upadhyay, $心 20)$ without any concern about what technological and management challenges of blockchain ado ${ }^{r}$ tion that need to be explored and understood for operational excellence in the automoti : is dustry context? Some studies have identified the challenges of the blockchain (Upadhyay, 20?0) $v$ be major barriers

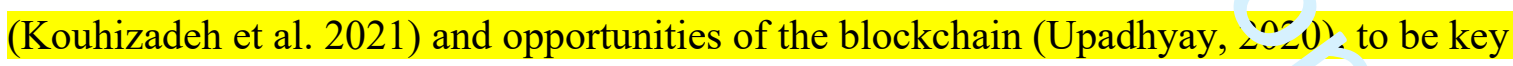
drivers for blockchain adoption in different areas (Kouhizadeh et al. 2021), wh11 , ol e of the researchers in the UK has explored blockchain applications as the key technology for busiress and management practitioners (White, 2017). 
The classification and differentiation of challenges and opportunities of blockchain adoption Into technological and management challenges and opportunities in the present study

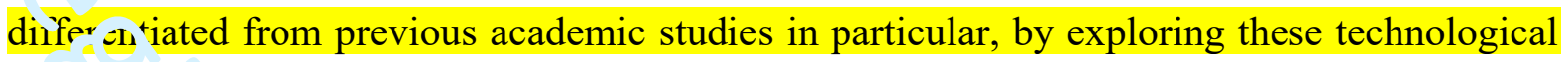
and $\mathrm{man}^{-}$su nent challenges and opportunities from the TOE framework angle for operational excellence ir the JK automotive industry context (Cole et al. 2019; Wang et al. 2019a) as shown in the fin ${ }^{\prime}$ ings and limitations of related studies in Table 4 of the present study. Though there are limited stı die r that have focused on the use of TOE framework to explore different factors that influence b ock shain adoption outside the UK in different companies (Clohessy and Acton, 2019) and chalı ses and opportunities that can influence blockchain adoption in different industries such as freig it logic tics industry (Orji et al. 2020) that have been published in different academic journals. Yet, the $\_$studies are fragmented because they did not include significant technological and managen es $\mathrm{t}$ ch sllenges and opportunities of blockchain adoption in the context of operational excellence, nor i $\uparrow$ ley consider to explore these challenges and opportunities in the automotive industry context. T.1ough it was stated in the future studies of Orji et al. (2020) that other industrial sectors can be str is to have a clear understanding of the critical factors to the blockchain adoption process. Th srefinre, the present study found a significant gap that exists in the literature regarding the techno' ${ }^{1}$ gical and management challenges and opportunities of blockchain adoption from the TOF. rramework for operational excellence in the automotive industry as shown in Table 4.

\section{Discussion}

Following the main findings, RQ1 is addressed in the following:

3. RQ1. What are the technological and management challenges and opportunities of blockchain adoption from the lens of the TOE framework for operational excellence in the UK automotive industry? 
5.1. The Management and Technological Challenges and Opportunities of Blockchain Technology Adoption Through The Lens of Technology - Organisation Environment (TOE) Framework for Operational Excellence

\subsubsection{Technological Context}

The technological context comprises technological equipment, processes and infrastructure. Blockchain as a distributed ledger technology promises to improve the automotive industry to achieve operational excellence (Kouhizadeh et al. 2020) in such a way that it will eliminate a lot of shortcomings of the traditional supply chain (Delafenestre, 2019; Wang et al. 2019a), it will enable the sustainable supply chain management (Saberi et al. 2018; Kouhizadeh et al. 2021), enable circular economy (Kouhizadeh et al. 2020), enhance efficiency, reduce paperwork, lower costs, lower workload, and contribute to customer satisfaction such as customer order management, show order traceability and enhance visibility for different supply chain participants (Martinez et al. 2019). Blockchain is decentralised and encompasses data server that is not controlled by a single firm.

\subsubsection{Blockchain technological challenges}

\subsubsection{Open network designs challenges}

Studies revealed that open network in blockchain designs can draw criminals, make it easy for illegal activity and possibly let access to content (O'Leary, 2017; O'Leary, 2018). For example, research article shows that based on public peer-to-peer blockchain those that aim to adopt blockchain technology who are interested in legal transactions and legal collaborators or participants might not be able to implement blockchain for their operations due to how easy it 
is to disguise transactions that are used to capture illegal transactions (O'Leary, 2018). itowever, due to the criminality on this open network design that will draw criminals to pe, fn' 1 a illicit transaction, implementing predictive capacity and a machine learning system that caı coct and analyse data automatically from blockenain bitcoin and other external data sources and apply search criteria to fit, index, and a cluster is an ideal approach to detect suspicious behaviour (Yin et al. 2019). This may pose a serious challenge to various stakeholders who are in the operations and supply chain of the firms to participate in using a blockchain platform, which may, in turn, hinder the firms to achieve operational excellence.

\subsubsection{Blockchain security and privacy challenges}

One of the technological challenges facing blockchain is the security challenges (Kouhizadeh et al. 2021) from the attacker (Warkentin and Orgeron, 2020), individual personal information and privacy of the individual from those who created blockchain (Upadhyay, 2020). However, irrespective of the decentralised transparent structure of blockchain technology, the present study finds that blockchain technology is still vulnerable to manipulation, which means there are security challenges in the blockchain. For example, empirical research conducted by Herian (2017) revealed that as the block is chain to the next as well as the one before it, it becomes less likely that a greedy attacker looking to intermeddle with a chain to defraud, would be able to undo or change a particular chain without affecting all the blocks associated with it. Another security challenge includes " $51 \%$ attack" in blockchain (Warkentin and Orgeron, 2020; Kamble et al. 2019; Chang et al. 2020a). This means that an attacker controls 51 per cent of the computing power of the entire participant network and could vote to remove all the participants, which is hypothetical for such an attack (Warkentin and Orgeron, 2020; K ${ }^{.}$.nble et al. 2019). 
Also, it was revealed that irrespective of how private or closed blockchain provides more privacy for the transaction (Morkunas et al. 2019), it was found that the privacy of transactions hisior. of individual blockchain has been a concern in which transactions histories of indivicial' ${ }^{1}$ lockchain are not as private as personal financial management such as bank accounts and often closely guarded and privacy of individual blockchain user identities, as well as the general anonymity enjoyed by those who facilitate the proliferation of blockchain architecture according to the empirical research by Herian (2017). Therefore these concerns can be worrisome for automakers stakeholders or actors who are contributing to the operational excellence of the firms to join the blockchain. Without various stakeholders who involved in the operations and supply chain, the aim to achieve operational excellence might not be possible.

\subsubsection{Wasted resources or energy consumption challenges}

One of the critical challenges facing the adoption of blockchain technology is being regarded as an extent of computing resources and energy consumption (O'Leary, 2017; Kumar et al. 2020; Min, 2019). Since blockchain technology underpins bitcoins and uses Proof of Work as a consensus algorithm (Nakamoto, 2008), the energy that Bitcoin consumes (Chang et al. 2020a) has been compared to the electricity consumption in the country of Ireland according to Siegfried et al. (2020) and O' Leary (2018). Similarly, it has been reported that the energy required to manage one Bitcoin transaction is equal to that required to power nine households in the United States for one day (Frizzo-Barker et al. 2020). Moreover, hydroelectric dams in China has been reported to power the largest Bitcoin mines in the world as discussed by FrizzoBarker et al. (2020). The blockchain energy consumption can be one of the concerns fo* manufacturers such as car manufacturers because their operations have been consuming electricity already (Mohamad and Songthaveephol, 2020). A lot of manufacturers such as car 
manufacturers might not want to use blockchain due to how it consumes energy, which may, in turn, stand as a barrier for adopting and implementing this technology for their operations such s s tracing their raw materials from the origin of the product, manufacturing of the products, and selling the completed products to the end customers.

\subsubsection{Lack of interoperability challenges}

Even if interoperability has been indicated as one of the keys to widespread blockchain adoption as asserted by Frizzo-Barker et al. (2020) that involves a partnership between tech firms and regulators to identify widely known protocols and industry standards, the technical elements of interoperability have been argued as one of the adoption barriers. Blockchain technology provides a share identification of devices from birth, interoperability, and projection. Interoperability has been characterised as one of the concepts of industry 4.0 (Garay-Rondero et al. 2019). Interoperability means free communication between blockchain systems. Since interoperability is one of the key properties that are central to blockchain technology, the question is being asked by researchers regarding interoperability. For example, questions such as if interoperability can communicate with other blockchains, The internet of Things, etc? (De Keyser et al. 2019). Such question might be asked because the majority of the blockchains in the market are currently working in silos (Warkentin and Orgeron, 2020; Bumblauskas et al. 2020; Di Vaio and Varriale, 2019) unable to pull or send information from existing IT system or integrate with existing IT systems (Wang et al. 2019a).

Deloitte as one of the blockchain vendors reported that the lack of interoperability gives independence to blockchain developers and coders and can give headaches to IT departments when they discover that without translation assistant platform cannot communicate anı interoperability appears to be critical in building the network effect within the business 
ecosystem (Upadhyay, 2020) Interoperability in blockchain can be categorised as one of the .nost pressing managerial challenges (Min, 2019). Due to these challenges, the present research finds in't effort has been developed for managers to overcome these challenges in the area of the suf $\mathrm{f}^{\mathrm{r}}$ - hain, which requires data interoperability among multiple organisations between diverse IoT over a supply chain (Kim and Laskowski, 2018; Pólvora et al. 2020). Therefore, blockchain interoperability may not communicate with most of the UK automakers' existing network and if firms wish to navigate the rapid financing options directly via their Enterprise Resource Planning ERP system, they may need to incorporate smoothly into these new systems, which can impact their operations and give their IT department a headache.

\subsubsection{Scalability challenges}

Storage capacity and scalability are part of the critical management challenges facing blockchain technology (Upadhyay, 2020; Chang et al. 2019a; Chang et al. 2020a; Min, 2019; Biswas and Gupta, 2019). It was reviewed that in the first year of Bitcoin, Bitcoin faced technological challenges such as important in increase in mining costs, the average block size, median confirmation time, mempool transaction count, and user fees (Manski, 2017). Though the mempool transaction account was asserted to be one of the unresolved technical challenges in the work of Manski (2017). Since blockchain underpinning Bitcoin as one of the cryptocurrencies that have been widely used and revealed in different studies (Morkunas et al. 2019), and one of the approaches and applications of blockchain (Ying et al. 2018; Wang et al. 2019) to carry out monetary transactions by individuals that adopt its use by putting nearly all of their transactions on the public blockchain (White et al. 2020), the chain grows constantly at a rate of $1 \mathrm{MB}$ for each block every 10 minutes (O'Leary, 2017), while there are c( r.es that are stored amongst the nodes in the network (Easley et al. 2019). 
It was explained by O' Leary (2017) that in Bitcoin, blockchain transactions need to be verified jy miners that ultimately create that mined roughly every 10 minutes. By taking into account the or ow whelming quantity of transactions that take place through a manufacturer's operations and $\operatorname{su}_{\nu} \mathrm{p}^{1-}$, hain, including locations, products, and different business partners, theoperations of firms need to be accessible to the demand of a firm service and the technology needs to perform these transactions immediately. Because the transaction rate for blockchain needs to be far higher until blockchain can handle today's business operations that are rapidly changing involving sales of products via various geographical locations.

\subsubsection{Blockchain technological opportunities}

\subsubsection{Disintermediation of third-party service provider opportunities}

It has been revealed by Schuetz and Venkatesh (2019) that it has the potential to minimise the need for intermediary institutions such as banks and lower the cost of transactions. They also argued that blockchain can provide customers with more suitable products in three ways: (1) digitalising traditional practices; (2) solving existing problems; (3) opening up new opportunities for users. Also, smart contract as one of the applications of blockchain has been reviewed by different researchers as one of the applications of blockchain that can bridge the gap of a third service provider (Shermin, 2017; Manski, 2017; Herian, 2017; Wang et al. 2019b; Ali et al. 2020). For example, Herian (2017) explained that smart contacts offer several distinctive opportunities to enhance current legally binding relations, such as minimising threats to those relationships which generally require legal intervention.

Though different questions have been asked on smart contract such as when are customer; willing to convert to smart contracts? To what extent do smart contracts enhance service $c_{1}$ ual $^{\dagger}$ iy level (e.g. convenience, speed) (De Keyser et al. 2019). However, empirical research conduch : 
by Chang et al. (2019b), which concentrated on both the feasibility and initiation of supply -nain application processes showed the proposed of the blockchain-based framework together Wlih t'a use of smart contracts to extract the viable advantages of the process design of the supply in -2 . Through a descriptive layout of a unified system, they presented a potential use case for the disintermediation of business operations through a conceptual, shared knowledge ledger. Also, they claimed that this ledger not only promotes or facilitates tracking information sharing, but it facilitates a multilateral collaboration network among supply chain participants or members. Similarly, smart contract, which has been reviewed as one of the ground-breaking characteristics of blockchain technology known as one of the of applications and the use of blockchain can enhance supply chain contract formation to prevent contractual disputes that can result from fraud, misunderstanding, and performance failures that can destroy the supply chain partnership and supply chain activities (Min, 2019).

Academic literature revealed the smart contract can send a payment to a supplier as soon as a shipment is received by buyer Wang et al. (2019a). One of the opportunities of smart contract in blockchain technology is that it can trigger non-functioning lawyer's activities by establishing a legal agreement between two parties that are willing to do business together and allows independent partners in mediation transactions without having to trust another party (Upadhyay, 2020).

\subsubsection{Transaction cost reduction opportunities}

One of the opportunities of blockchain technology is that transactions or payment can be made without the third service providers such banks to avoid paying high commission fee when making overseas payment (Ahluwalia et al. 2020; Schuetz and Venkatesh, 2019; Upadh; ay 2020). One of the truths about blockchain technology according to Iansiti and Lakhani (20 7) 
is that it can dramatically reduce the cost of transactions, in particularly, blockchain technology van be adopted to reduce the cost of supply chain transactions (Cole et al. 2019). Based on the findir $y_{i}$ of a research by Holotius et al. (2019), they revealed that since blockchain technology enables $r$ soi reduction, increasing efficiency would solve the growing costs of compliance and enable more , trea nlined enforcement due to greater transparency. They cited an example that the know-your-c'stomer process can be simplified or streamlined, resulting in lower costs, too. Additionally, they $\cdot \operatorname{rg} r: \mathcal{d}$ that faster transaction execution leads to reduced default risk and thus to lower cost.

\subsubsection{Security opportunities}

Though security has been argued as 'ne $\mathrm{f}$ the technological challenges of blockchain adoption (Kouhizadeh et al. 2021). Fascinating y, sccurity is one of the opportunities that blockchain aims to provide for the customers (Kouhizadph $\epsilon^{`}$ al. 2020). This is supported by the research conducted by Wang et al. (2019a) as their findings ' nowed that blockchain can enhance data security for information sharing such that the data sc u ur' $\mathrm{v}$ and protection provided by blockchains also protect against cybercrime and fraud. Tr - y argued that blockchain will provide direct transparency of shipments to customs authorilies $\because$ real times, positively enhancing the relevant information or data for risk identification, s? ety, and security control. Security opportunities provided by the blockchain would enable custum ${ }^{\prime}$ ? to make a direct payment to suppliers of their products in a secure way without a third serr ce rovider (Wang et al. 2019a). Kouhizadeh et al (2020) argued that blockchain technology compri॰ ss a particular system layout where data can only be added to the ledger, while data history remulnc. They asserted that the security that will be performed on of blockchain will improve sustain.mole standards where customers will be ensured the sources, activities performed, and authentici $y$ 
or provenance of the green products and goods. These activities may, in turn, enhance the operational excellence of the firm.

\subsubsection{Organisational Context}

Organisational context is descriptive and relates directly to the usage and availability of resources (Ali et al. 2020). The propensity for technology adoption is influenced by informal and formal intra-organisational contact and control mechanisms (Ahmadi, et al., 2018); as well as organisational resources and innovativeness (Abed, 2020). The important organisational variables include infrastructure and expertise, technology or innovation support, technological resources, knowledge capability, technological infrastructure (Aboelmaged, 2014), innovation capacity, and top management (Orji et al. 2020). Therefore, lack of advanced level of blockchain technical expertise challenges, knowledge sharing management opportunities, supply chain management opportunities, and new business model opportunities provided by the blockchain can influence firms in adopting blockchain.

\subsubsection{Blockchain management challenges}

\subsection{Lack of advanced level of blockchain technical expertise challenges}

It was revealed in the previous and recent academic literature that lack of technological expertise may hinder the effective implementation of blockchain technology as one of the new age technologies (Kumar et al. 2020; Upadhyay, 2020; Min, 2019). Similarly, it was found that a lack of technical expertise in blockchain technology is one of the barriers in terms of blockchain technology adoption (Kurpjuweit et al. 2019). Blockchain technical expertise is required to manage blockchain technology effectively (Manski, 2017). This research finds that blockchain technology could be determined through individual, academics, and most 
importantly practitioners in blockchain technology (White, 2017). Blockchain will not go far when there is a lack of expertise or talent for blockchain or knowledge of blockchain.

Ther ic $^{*}$, to use blockchain to achieve operational excellence in terms of tracking of raw materials in $\mathrm{m}$ the origin of the product to the plant would be difficult to achieve. It was shown that the creat ${ }^{*}$ on $o^{c}$ blockchain applications is still isolating the ability of the average user and centralises the $\mathrm{p} r$ wer to decide regarding the type of blockchain applications that are created by developers (Ma1 ski 2017). The present study finds that lack of expertise in the area of blockchain technology is al o limited from academics and individuals, which was indicated as one of the limiting factors in *'Ae ^mpirical study conducted by White (2017) as it was revealed in the study that the lack of kno rledge of blockchain principles seems to limit the ability of panel members to picture the future of applications of blockchain in his research.

\subsubsection{Blockchain management opportunities}

\subsection{Knowledge sharing management opportunities}

The recent advances in blockchain development have 'ees revealed as a technology capable of secure, distributed information, and knowledge sharing re wirement ( $\mathrm{Li}$ et al. 2018; Chang, et al. 2020a). When data is managed securely it will give custcmer rest assured and confident on the firms. Data in blockchain can be used in various ways to achıeve ,perational excellence. For example, the findings of a research analysis by Holotius et al. (20!y) s'ygested that blockchain could be used to offer data analytics to provide deeper insights in ${ }^{4} \mathrm{~J}$ nayments, which contributes to enhanced fraud detection and prevention. It can enable a veruı ? and standardised approach in achieving a higher level of sharing between producers (Li c al. 201 8). According to Wang et al. (2019a) blockchain refers to a distributed data infrastructure c method for recording data using the crypto-analytic hash function. For example, academic 
research revealed that blockchain technology can create quite notable opportunities for data ınanagement (López and Farooq, 2020). Using blockchain will enable firms to manage their operations data securely.

\subsection{Supply chain management opportunities}

Blockchain redur's transaction fees, asset integrity, fraud detection and prevention, P2P connectivity, imprc ved order to fulfilment, and increased trust among supply chain partners (Min, 2019; Delafenest ¿, 2 219). Blockchain is increasingly receiving attention in the area of supply chain management. $\mathrm{Tr}$, opportunities of blockchain technology in the supply chain were revealed, which include ex enced visibility and traceability, supply chain digitalisation and disintermediation, data security, anc smart contract (Wang et al. 2019a). Traceability of the raw materials and products to the 91.'ı can be achieved through blockchain-based traceability, which may, in turn, enhance the tracitional tracking operation systems of the car manufacturers (Kouhizadeh et al. 2020). One of th findings of survey research revealed that implementation of blockchain has a significant posiıve influence on consumer's purchasing decisions, mediated by consumer's quality perceptions (S ^naers et al. 2018). It was critically examined that blockchain technology and smart contract are $\mathrm{po}^{+}$-ntial application to supply chain management to gain supply chain sustainability (Saberi et al '́018), which may, inturn, contribute to environmental performance Also, traceability of the produr is has been part of the operations of car manufacturers and tracking of products recall are essenti $1 \mathrm{l}$ it the automotive industry. Therefore, blockchain-based traceability in the supply chain can do $t^{h} . \mathrm{s}$ job for car manufacturers.

\subsection{New business model opportunities}


Blockchain is one of the technologies that can create a new business model (Holotius et al. L019). It was asserted that inventors of new business models can use blockchain in their new

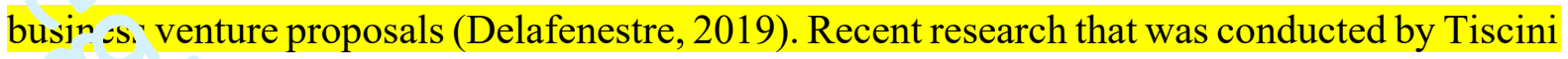
et al. ( $\left.2 \mathrm{O}^{?}, \mathrm{v}\right)$, which explored the potential innovation of blockchain technology has shown that not only app ${ }^{1}$. atiı ns of blockchain would create new business model, but there is a propensity to create sustain vle business model innovation. Car manufacturers aiming to achieve operational excellei ce $\therefore$ the area of traditional supply chain management and customer satisfaction, new technılog es such as blockchain most likely to create a sustainable

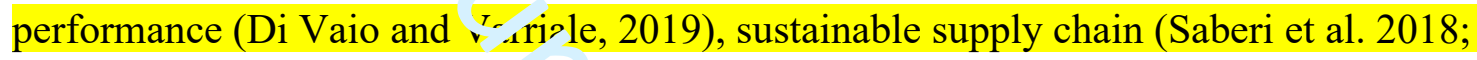
Kouhizadeh et al. 2021), new s( rvices, new products, and enhance customers' experience to

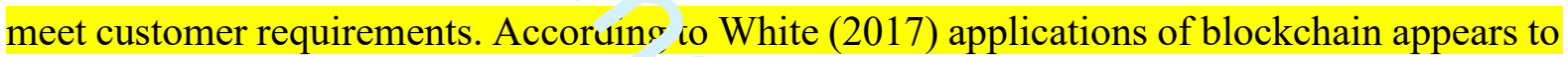
offer considerable performance impro re nen' and commercialisation opportunities. For example, these opportunities include handl ${ }^{1}{ }_{\varepsilon}^{\top}$, ransaction beyond the traditional financial transaction, blockchain can be used to prove aut _ntication between exchanges, such as for digital content (Miau and Yang, 2018) etc.

The present research finds that entire new business could $b: \mathrm{g}^{\mathrm{r}}$ wn through blockchain (Upadhyay, 2020) in terms of being reached and served an existir s : ustomer, the value could be created for customers, firms can communicate with and reach th $\mathfrak{u}^{\prime \prime} r$ astomers' segments to deliver value proposition with reduced or eliminated middle or third $p^{2} . \mathrm{y}$. it can enhance a relationship that firms established with specific customer segments by acquirın ${ }_{2}=$ istomers and retain a customer or to boost sales, technology firms that provides blockchain-r€ $\mathrm{a}_{i} \mathrm{\perp}$ professional services can generate revenue from network transaction fees, business custr ${ }_{\text {.ner }}$ support level agreements, or software-as-a-service ( SaaS) contracts platform fees etc (Morkunas et al. 2019). According to De Keyser et al. (2019), the rise of the blockchain- 
enabled smart contract also opens significant opportunities to service innovation and new uusiness model. Likewise, empirical research findings, which is based on the Delphi study by Hulntiu et al. (2019) found that blockchain paves the way for new business models and makes certain e is ing business models obsolete. For example, one of the ways that blockchain can enhance cert ،n e risting obsolete business model is to make existing intermediary reduced (Anagnostopoulos, 2018).

\subsubsection{Environmental: External Context}

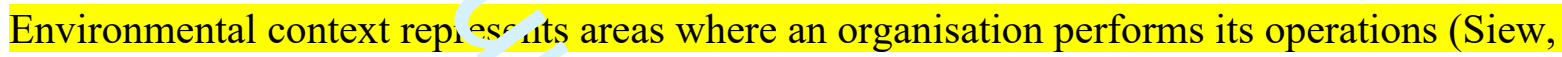
et al., 2020), with the primary co ıcern provided to external forces such as governments regulation and laws (Kouhizadeh et al. 021) can influence the adoption of blockchain in the automotive industry. Therefore, govı rı nıent regulatory and legal issue challenges are considered as an environmental factor that th; $\sim$ it dustry needs to be considered when planning to adopt and implement blockchain. It was asserter by Kouhizadeh et al. (2021) that government regulations are not yet completely suppurti $\rightarrow$ of blockchain technology, despite the technology's novelty hampers its adoption in the sur ply chain. This is supported by the research study conducted by Chang et al, (2020a) in the area of ${ }^{s}$ nancial services. They revealed in their study that some governments are still restricting the ase of blockchain payment systems such as cryptocurrencies. Because some of these governments ir a eir countries regard cryptocurrencies such as Bitcoin as unconstitutional or illegal coin ( $K_{\text {: }}$ ria: is et al. 2020). Though the use of cryptocurrencies in some countries is unrestricted (Chang, et il. 2020a). Therefore, exploring government regulatory and legal issue challenges as an eıvir unmental factor that can affect the adoption of blockchain in achieving operational excellenc in $^{\text {this }}$ industry is considered in the present study. 


\subsubsection{Government regulatory and legal issue challenges}

I ${ }^{+}$va ; asserted in the work of Orji et al. (2020) that government policy and support is an in: lu ?ııа ${ }^{1}$ nvironmental factor of blockchain adoption. It was explained that regulatory issue has beer, one the challenges that are impacting the adoption of blockchain technology (Yeoh, 2017; Tang, t al 2020). Also, the contracting party to the smart contract was described as a digital account $\mathrm{ra}^{4}{ }^{4}$.er ${ }^{+1}$ an a real individual as well as a variety of legal issues arise (Jianchao et al. 2020) because I Ir ckchain has ever been applied to any legal or regulatory background (Herian, 2017). On the otner iland, blockchain was predicted by Min (2019) that since blockchain technology relies on the distributed ledger that can bypass the interference of government; the government may icrease pressure on blockchain technology through different regulations and legal restric ${ }^{\mathrm{r}}$ is and thus may hinder the usefulness of blockchain technology for ensuring the integrity and privacy of transactions and asset transfers. This is supported by the work of Helo and Hao (2019, as ney argued that regulatory restrictions, for example, have hindered the rollout of smart contracts, ${ }^{*}$.nich is one of the applications of blockchain in several countries. Since there is no obligat ${ }^{*} \mathrm{n} r \mathrm{n}$ blockchain-supported firms to abide by data privacy laws in different countries, Biswas ar d $\curvearrowright$ upta (2019) asserted that Businesses built on blockchain platforms can face enormous $m$; ation costs following the adoption of country-wise regulations.

It was revealed in the general findings of research conducted by Ciaido $e^{+}$al. (2021) that blockchain and its potential benefits for information security are yet to be cri:dered by the organisation as an evolving technology, without relevant regulation and is not y : $\mathrm{c}$. illy understood. Therefore, government regulation and support are significant in this context $\mathrm{r}^{\mathrm{d}} \mathrm{d}$ it includes the willingness of different government agencies aimed at proving assistanc ? $.1 d$ implement rules and regulations to promote the adoption of blockchain technology in th.e 
automotive industry. Though a report by the UK government has predicted that the adoption of plockchain technology would play a significant role in the UK where the technology might tran ${ }^{f}$ งı $\mathrm{n}$ "financial markets, supply chains, customer and business-to-business services, and publiciy-' 'ci I registers" (Government Office for Science, 2016). Therefore, there still hope that the UK gove nme at may reduce the pressure on using various features of blockchain such as blockchain-baser' payment systems, blockchain-based smart contracts etc for industries, in particular, the auto not $\because$ industry in which the firms and customers can be using the systems for the transactions in tl e $\mathrm{L} K$ since smart contracts as one the applications of blockchain, for example, may permits fast a a $^{\prime}$ direct payment from customers to suppliers (Wang et al. 2019a) may, in turn, contribute to operi tional excellence. The UK automakers may as well consider the adoption and implementation of olor kchain for their supply chain operations such as using blockchain-based payment systems tian inc'ude cryptocurrencies for transactions and cross border payment in the future.

\subsection{Research Implications}

\subsubsection{Theoretical implications}

There has been increasing attention on the study of challe tges and opportunities of blockchain adoption (Upadhyay, 2020) in different industries such as finar.jia! industry (Schuetz \& Venkatesh, 2019), fright logistics industry (Orji et al. 2020), while ...ers are limited studies that have focused on the use of TOE framework to explore different fa $\mathrm{\iota O}_{1 \mathrm{~s}} \mathrm{~s}$ hat influence blockchain adoption for different companies (Clohessy and Acton, 2019), $\mathrm{t}$, ex ,lore challenges and opportunities that can influence blockchain adoption in different industries such as freight logistics industry (Orji et al. 2020) that have been published in different academi, journals. Yet, these studies are fragmented because they did not include significant technological '..n' management challenges and opportunities of blockchain adoption in the context of operatio ral 
excellence, nor do they consider to explore this approach in an automotive industry context. i hough it was stated in the future studies of Orji et al. (2020) that other industrial sectors can be $s^{\text {tr }}$ ui 2 d to have a clear understanding of the critical factors to the blockchain adoption process. Tin refore, the literature of challenges and opportunities of blockchain adoption was brought forward in the present study in two ways:

1. There have been no studies yet that have systematically reviewed the technologicaland management challenges of blockchain adoption for operational excellence (Cui, et al., 2020). The present study presents technological-organisational-environmental (TOE) framework as a set of challenges and drivers of adoption of new technology, which aimed at identifying and understanding the technological and management challenges and opportunities of blockchain adoption in operational excellence.

2. The present study extends the literature of challenges and opportunities of blockchain technology adoption and differentiates the technological and management challenges and opportunities of blockchain adoption incorporating the theory of TOE framework.

\subsubsection{Managerial implications}

Even if it has been revealed that Toyota as one of the cal $\mathrm{m}^{\text {r. }}$-'Ifacturers has implemented blockchain technology in its internal supply chain networks, mark_ting communication, and

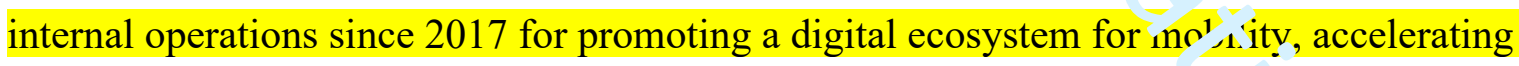
autonomous driving technology, and enhancing its business intelligence (Ko hizadeh, et al., 2020), our findings also have significant managerial implications and insights th At $_{\text {can }}$ enable companies such as carmakers that have yet to adopt and implement blockchain tu $u^{r}$ uerstand technological and management challenges and opportunities of blockchain adoptio. in ${ }^{+}$wo way: 
1. The findings are considered to benefit government, blockchain service providers, in particular, the automotive industry to focus specifically on the high rated critical factors identified in the present study to adopt and implement blockchain successfully.

2. Operations managers in the automotive industry may implement the systmtic direction of implementation perspectives into the important parts for the blockchain adoption to help develop successful strategies for competitive advantage.

\subsection{Conclusion and Limitations}

Existing academic studi is o' technological and management challenges and opportunities have been thoroughly searched, $1 w^{*}$, erred, and discussed through the lens of technology organisation - environment (TO E) fiar.ework. Different academic articles were selected from the reliable online database and cattgor; sed into different areas. The present systematic literature review provides an overvieu a ld u iderstanding of studies on technological and management challenges and opportunities of $v^{\prime} \mathrm{x}$ kchain adoption and its technical application and implications for the automotive industry.

There are some limitations that the present study facen vine of the limitations is that the journals used in this study are limited to 35 journals and tie arademic articles selected are limited to 71 articles through the specific keywords. However in t.1ore journals and articles were included by expanding the search it could have provided a $\mathrm{m}$,re omprehensive opinion of the issue explored. Likewise, a lack of several journal articles on blr _kchcin technological and management challenges and opportunities articles affected the sample siz ; to be studied for operational excellence research, in particular, in the automotive industry. $T^{1}$. e $s^{\dagger} u d y$ has been explored in the UK automotive industry context and the outcome is the limitat: on of generalization to the rest of the countries and industries. Systematic literature approacn $r$ as considered for the present study to explore existing academic papers on technological and 
management challenges and opportunities from the lens of TOE framework for operational excellence, whereas a more specified method meta-analysis can be considered for future rese $\mathrm{i}$. The environmental context of the TOE framework used in this study gave high priority ${ }^{+}{ }_{2}$ rovernment regulatory and legal issues challenges without any concern about customer pre sure and competitive pressure, which may provide some significant and additional direct; $\mathrm{nns}$ for future studies as well as further studies studies of the topic in this industry.

\subsection{Future research directions}

Since blockchain is still in I: 1 arcent stage, it is obvious from the present study that there is limited research in exploring ci regurics and differentiate its technological and management challenges and opportunities based un $t^{t}$.e analysis conducted for the present study. However, this provides many directions for fu. $1 \geq 2$ re earch. The blockchain technological and management challenges and opportunities $f_{\jmath_{1}}$ ' perational excellence in the context of the automotive industry have not received increase $a^{t^{+}}$.ntion compare to other industries such as the financial industry across the globe. Exploring $m^{r}{ }_{1}$ study in this area can provide the automotive industry with an insight into the uses of bloc' chain. Also, blockchain technology has received increasing attention from different researchers in tie Sinancial institutions, business and management etc, more study can also be explored it the automotive industry. This gap can be filled by investigating different carmakers in adopting 'slock zhain technology from the theoretical angle such as TOE framework. Subsequently, the stu y v ould show if there is a great future in blockchain technology within the automotive industry as hlockchain has been hyped by expertise, academics, journalists etc.

Figure 5 highlights some industry specific papers addressing blockchain issues in wnir'.1 ve were unable to map the addressed issues with respect to block chain adoption affect ing 
operational performance. The future research may extend this area and map the addressed ıssues with respect to blockchain adoption affecting operational performance. Finally, how fuur ${ }^{\prime}$ 'chnological and management challenges and opportunities of blockchain can be more explored in'y be expected to be studied for operational excellence in the UK automotive industry, suc'. as ı' 'hat of "how blockchain may be expected to change the future business" that was examined $b$, White (2017), may likewise be examined from an operational excellence perspective in the future.

\section{References}

Abed, S. S., (2020), "Social commerce adoption using TOE framework: An empirical investigation of Saudi Arabian SMEs", International Journal of Information Management, Vol. 53, pp. 102-118.

Aboelmaged, M. G., (2014), "Predicting e-readiness at firm-level: An analysis of technological" organizational and environmental (TOE) effects on e-maintenance readiness in manufacturing firms", International Journal of Information Management, Vol. 34 No. 5, pp. 639-651.

ABS, (2010), "Academic Journal Quality Guide", Available at:https://charteredabs.org/wpcontent/uploads/2015/05/2010-Journal-Guide.pdf (Accessed 3 March 2019).ABS,

(2015), "Academic Journal Guide 2015", Available at: https://gsom.spbu.ru/files/abslist-2015.pdf (Accessed 2 Mrach 2018).

ABS, (2018), "Academic Journal Guide", Available at: https://harzing.com/download/jql_20180403_title.pdf(Accessed 3 March 2020).

Adams, R., Parry, G., Godsif, P. and Ward, P., (2017), "The future of money and further applications of the blockchain", Strategic Change, Vol. 26. No. 5, pp. 417-422.

Agarwal, N., Grottke, . M., Mishra, S. \& Brem, A., ( 2017), "A Systematic Literature Review of Constraint-Based Innovations: State of the Art and Future Perspectives". IEEE Transactions on Engineering Management, Vol. 64 No. 1, pp. 3 - 15.

Ahluwalia, S., Mahto, R. V. \& Guerrero, M., (2020), "Blockchain technology and startup financing: A transaction cost economics perspective", Technological Forecasting and Social Change, Vol. 151, pp. 119-854.

Ahmadi, H. et al., (2018), "The moderating effect of hospital size on inter and intraorganizational factors of Hospital Information System adoption", Technological Forecasting and Social Change, Vol. 134, pp. 124-149.

AI-Saqaf, W. and Seidler, N., (2017), "Blockchain technology for social impact: opportunities and challenges ahead", Journal of Cyber Policy, Vol. 2 No. 3, pp. 338-354.

Ali, O., Ally, M., C. and Dwivedi, Y., (2020) "The state of play of blockchain technology in the financial services sector: A systematic literature review", International Journal of Information Management, Vol. 54, p. 102199.

Ali, O., Shrestha, A., Osmanaj, V. and Muhammed, S., (2020), "Cloud computing technology 
adoption: an evaluation of key factors in local governments", Information Technology and People, ahead-of-print (ahead-of-print), pp. 1 - 38.

Anagnostopoulos, I., (2018), "Fintech and regtech: Impact on regulators and banks", Journal of Economics and Business, Vol. 100, pp. 7-25.

Angelis, J. and da Silva, E. R., (2019), "Blockchain adoption: A value driver perspective", Business Horizons, Vol. 62 No. 3, pp. 307-314.

Atewolohun, D., Roxanne, K., Elena, D., Deirdre, A., and Ruth, S., (2017), "Individual-level Foci of Identification at Work: A Systematic Review of the Literature", International Journal of Management Reviews, Vol. 19 No 3, pp. 273-295.

Bailey, D. and Propris, L. D., (2017), "Brexit and the UK Automotive Industry" National Institute Economic Review, Vol. 242 No. 1, pp. R51-R59.

Behnke, K. and Janssen, M. F., (2019), "Boundary conditions for traceability in food supply chains using blockchain technology", International Journal of Information Management, In Press(Corrected Proof), pp. 1-10.

Benito, J. G., Lannelongue, G. and Alfaro, J. A., (2013), "Study of supply-chain management in the automotive industry: A bibliometric analysis", International Journal of Production Research, Vol. 51 No. 13, pp. 849-3863.

Bhaird, C. M., Robyn, O., Sarah, D. Dodd., Juliette, W., and Angelo B., (2019), "Small beer? peer-to-peer lending in the craft beer sector", Strategic Change, Vol. 28 No. 1, pp. 5968.

Biswas, B. and Gupta, R., (2019), "Analysis of barriers to implement blockchain in industry and service sectors", Computers and Industrial Engineering, Vol. 136, pp. 225-241.

Boukis, A., (2019), "Exploring the implications of blockchain technology for brand-consumer relationships: a future research agenda," Journal of Product and Brand Management, ahead-of-print(ahead-of-print), pp. 1-14.

Bumblauskas, D., Mann, A., Dugan, B. \& Rittmer, J., (2020), "A blockchain use case in food distribution: Do you know where your food has been?" International Journal of Information Management, Vol. 0 No. 0, pp. 102-008.

Caiado, R. G. G., Scavarda, L. F., Gavião, L. O., Ivson, Paulo., Nascimento, D. L. de. and Garza-Reyes, J. A., (2021), "A fuzzy rule-based industry 4.0 maturity model for operations and supply chain management", International Journal of Production Economics, Vol. 231, pp. 107-883.

Cai, C. W., (2018), "Disruption of financial intermediation by FinTech: a review on crowdfunding and blockchain", Accounting and Finance, Vol. 58 No. 4, pp. 965-992.

Caldwell, N. and Smallman, C., (1996), "Greening the Value Chain: Operational Issues Faced by Environment in the UK Car Manufacturing", Corporate Social Responsibility and Environmental Management, Vol. 3 No. 2, pp. 82-90.

Chang, S. E., Chen, Y.-C. and Lu, M.-F., (2019b), "Supply chain re-engineering using blockchain technology: A case of smart contract based tracking process", Technological Forecasting and Social Change, Vol. 144, pp. 1-11.

Chang, S. E., Chen, Y.-C. and Wu, T.-C., (2019a), "Exploring blockchain technology in international trade: Business process re-engineering for letter of credit", Industrial Management and Data Systems, Vol. 119 No. 8, pp. 1712-1733.

Chang, V., Baudier, P., Zhang, H., Xu, Q., Zhang, J., and Arami, M., (2020a), "How Blockchain can impact financial services - The overview, challenges and recommendations from expert interviewees", Technological Forecasting and Social Change, Vol. 158, pp. 120-166.

Chen, Y., (2018), "Blockchain tokens and the potential democratization of entrepreneurship 
and innovation", Business Horizons, Vol. 61 No. 4, pp. 567-575.

Chugani, N., Kumar, V., Garza-Reyes, J. A., Rocha-Lona, L. and Upadhyay, Arvind., (2017), "Investigating the green impact of Lean, Six Sigma and Lean Six Sigma A systematic literature", International Journal of Lean Six Sigma, Vol. 8 No. 1, pp. 7 - 32.

Clohessy, T. and Acton, T., (2019), "Investigating the influence of organizational factors on blockchain adoption: An innovation theory perspective", Industrial Management and Data Systems, Vol. 119 No. 7, pp. 1457-1491.

Cole, R., Stevenson, M. and Aitken, J., (2019), "Blockchain technology: implications for operations and supply chain management", Supply Chain Management: An International Journal, Vol. 24 No. 4, pp. 469-483.

Cui, L., Gao, M., Dai, J. and Mou, J., (2020), "Improving supply chain collaboration through operational excellence approaches: an IoT perspective", Industrial Management and Data Systems, ahead-of-print(ahead-of-print), pp. 1-27.

Culot, G., Orzes, G., Sartor, M. and Nassimbeni, G., (2020), "The future of manufacturing: A Delphi-based scenario analysis on Industry 4.0.", Technological Forecasting and Social Change, Vol. 157, pp. 120-092.

De Keyser, A., Alkire, L., Kandampully, J., Verbeeck, C. and Kandampully, J., (2019). "Frontline Service Technology infusion: conceptual archetypes and future research directions" Journal of Service Management, Vol. 30 No. 1, pp. 156-183.

Delafenestre, R., (2019), "New business models in supply chains: a bibliometric study", International Journal of Retail and Distribution Management, Vo.l 47 No. 12, pp. 1283-1299.

Demirbas, D. \& Wilkinson, L., (2018), "Supplier relations impact within the UK automotive industry", Benchmarking: An International Journal, Vol. 25 No. 8, pp. 3143-3161.

Denyer, D. and Tranfield, D., (2009", "Producing a systematic review," In: D. Buchanan and A. Bryman (Eds)The Sage handbook of organizational research methods. Los Angeles: SAGE, pp. 671-689.

Dhirasasna, N., Becken, S. and Sahin, O., (2020), "A systems approach to examining the drivers and barriers of renewable energy technology adoption in the hotel sector in Queensland, Australia", Journal of Hospitality and Tourism Management, Vol. 42, pp. 153-172.

Di Vaio, A. and Varriale, L., (2019), "Blockchain technology in supply chain management for sustainable performance: Evidence from the airport industry", International Journal of Information Management, Vol. 13, p. 102014.

Diestelmeier, L., (2019), "Changing power: Shifting the role of electricity consumers with blockchain technology - Policy implications for EU electricity law", Energy Policy, Vol. 128, pp. 189-196.

Dungan, K. J., (2012), "Design for Operational Excellence: A Breakthrough Strategy for Business Growth", New York: McGraw-Hill.

Easley, D., O'Hara, M. and Basu, S., (2019), "From mining to markets: The evolution of bitcoin transaction fees", Journal of Financial Economics, Vol. 134 No. 1, pp. 91-109.

Edgeman, R., (2018), "Excellence models as complex management systems: An examination of the Shingo operational excellence model", Business Process Management Journal, Vol. 24 No. 6, pp. 1321-1338.

Egi, F., (2020), "Renewable energy investment risk: An investigation of changes over time and the underlying drivers", Energy Policy, Vol.140, pp. 111-428.

Frizzo-Barker, J., Chow-White, P. A., Adams, P. R., Mentanko, J., Ha, D. and Green, Sandy (2020), "Blockchain as a disruptive technology for business: A systematic review", 
International Journal of Information Management, Vol. 51, pp. 102-029.

Fuchs, H., Aghajanzadeh, A. and Therkelsen, P., (2020), "Identification of drivers, benefits, and challenges of ISO 50001 through case study content analysis", Energy Policy, Vol.142, pp. 111-443.

Garay-Rondero, C. L., Claudia, L., Martinez-Flores, J. L., Smith, N. R., Morales, S.O.C. and Aldrette-M., (2019), "Digital supply chain model in Industry 4.0", Journal of Manufacturing Technology Management, ahead-of-print (ahead-of-print ), pp. 1-47.

Garza-Reyes, J. A., (2015), "Lean and green e a systematic review of the state of the art literature", Journal of Cleaner Production, Vol. 102, pp. 18-29.

Government Office for Science, (2016) "Distributed Ledger Technology: beyond block chain", London: Open Government Licence.

Gurtu, A. and Johny, J., (2019), "Potential of blockchain technology in supply chain management: a literature review", International Journal of Physical Distribution and Logistics Management, Vol 49 No. 9, pp. 881-900.

Habidin, F. N. and Yusof, S. M., (2013), "Critical success factors of Lean Six Sigma for the Malaysian automotive industry", International Journal of Lean Six Sigma, Vol. 4 No. 1, pp. 60-82.

Helliar, C. V., Crawford, L., Rocca, L., Teodori, C. and Veneziani, M., (2020), "Permissionless and permissioned blockchain diffusion", International Journal of Information Management, Vol. 54, pp. 102-136.

Helo, P. and Hao, Y., (2019), "Blockchains in operations and supply chains: A model and reference implementation", Computers and Industrial Engineering, Vol.136, pp. 242251.

Herian, R., (2017), "Blockchain and the (re)imagining of trusts jurisprudence", Strategic Change, Vol. 26 No 5, pp. 453-460.

He, Y., Li, H., Cheng, X., Liu, Y., Yang, C. and Su, L., (2018), "A Blockchain Based Truthful Incentive Mechanism for Distributed P2P Applications," IEEE Access, Vol. 6, pp. $27324-27335$.

Hohenstein, N.-O., Feisel, E. and Hartmann, E., (2014), "Human resource management issues in supply chain management research: A systematic literature review from 1998 to 2014, International Journal of Physical Distribution and Logistics, Vol. 44 No. 6, pp. 434-463.

Holotius, F., Pisani, F. and Moormann, J., (2019), "Radicalness of blockchain: an assessment based on its impact on the payments industry", Technology Analysis and Strategic Management, Vol. 31 No. 8, pp. 1-14.

Iansiti, M. and Lakhani, K. R., (2017), "The Truth About Blockchain", $\underline{\text { Harvard Business }}$ Review, Vol. 95 No. 1, pp. 118-127.

Jensen, J. K., (2012), "Product carbon footprint developments and gaps" International Journal of Physical Distribution and Logistics, Vol. 42 No. 4, pp. 338-354.

Jianchao, H., Che, W. and Sai, L., (2020), "How to improve the competiveness of distributed energy resources in China with blockchain technology", Technological Forecasting and Social Change, Vol. 151, p. 119744.

Kamble, S., Gunasekaran, A. and Arha, H., (2019), "Understanding the Blockchain technology adoption in supply chains-Indian context", International Journal of Production Research, Vol. 57 No. 7, pp. 2009-2033.

Kang, J., Yu, R., Huang, X., Maharjan, S., Zhang, Y. and Hossain, E., (2017), "Enabling Localized Peer-to-Peer Electricity Trading Among Plug-in Hybrid Electric Vehicles Using Consortium Blockchains", IEEE Transactions on Industrial Informatics, Vol 
13 No. 6, pp. 3154 - 3164.

Kher, R., Terjesen, S. and Liu , C., (2020), "Blockchain, Bitcoin, and ICOs: a review and research agenda", Small Business Economics, pp. 1-22.

Kim, H. M. and Laskowski, M., (2018) "Toward an ontology-driven blockchain design for supply-chain provenance", Intelligent Systems in Accounting, Finance and Management, Vol. 25 No. 1, pp. 18-27.

Kouhizadeh, M., Saberi, S. and Sarkis, J., (2021), "Blockchain technology and the sustainable supply chain: Theoretically exploring adoption barriers", International Journal of Production Economics, Vol. 231, pp. 107-831.

Kouhizadeh, M., Zhu, . Q. and Sarkis, J., (2020), "Blockchain and the circular economy: potential tensions and critical reflections from practice", Production Planning and Control, Vol. 31 No. 11-12, pp. 950-966.

KPMG, (2017), "The Digitalisation of the UK Automotive Industry - SMMT", available at: https://www.smmt.co.uk/wp-content/uploads/sites/2/smmt thedigitalisation-of-the-uk-auto-industry_kpmg-apr-2017.pdf (Accessed 20 May2019).

Kumar, A., Liu, R. and Shan, Z., (2020), "Is Blockchain a Silver Bullet for Supply Chain Management? Technical Challenges and Research Opportunities", Decision Sciences Journal, Vol. 51 No. 1, pp. 8-37.

Kumar, V., Ramachandran, D. and Kumar, B., (2020), "Influence of new-age technologies on marketing: A research agenda", Journal of Business Research, Vol. 0 No. 0, pp. 1-24.

Kurpjuweit, S., Schmidt , C. G., Klöckner, M. and Wagner, S. M., (2019),"Blockchain in Additive Manufacturing and its Impact on Supply Chains", Journal of Business Logistics, pp. 1-25.

Kyriazis, N., Papadamou, S. and Corbet, S., (2020), "A systematic review of the bubble dynamics of cryptocurrency prices", Research in International Business and Finance, Vol. 54, pp. 101-254.

Larios-Hernández, G. J., (2017), "Blockchain entrepreneurship opportunity in the practices of the unbanked", Business Horizons, Vol. 60 No. 6, pp. 865-874.

Li, J. \& Chang, X., (2020) Improving mobile health apps usage: a quantitative study on mPower data of Parkinson's disease", Information Technology and People, ahead-ofprint(ahead-of-print), pp. 1-22.

Lin, D., Lee, C. K. .., Lau, H. and Yang, Y., (2018), "Strategic response to Industry 4.0: an empirical investigation on the Chinese automotive industry", Industrial Management and Data Systems, Vol. 118 No. 3, pp. 589-605.

Liu, Y., Zhu, Q. \& Seuring, S., (2020), "New technologies in operations and supply chains: Implications for sustainability", International Journal of Production Economics, Vol. 229, pp. 107-889.

Li, Z., Wang, W. M., Liu, G., Liu, L., He, J., and Huang, G. Q., (2018), "Toward open manufacturing: A cross-enterprises knowledge and services exchange framework based on blockchain and edge computing", Industrial Management and Data Systems, Vol. 118 No. 1, pp. 303-320.

López, D. and Farooq, B., (2020), "A multi-layered blockchain framework for smart mobility data-markets", Transportation Research Part C: Emerging Technologies, Vol. 111, pp. 588-615.

Lowe, J., (1991), "Teambuilding Via Outdoor Training: Experiences From a UK Automotive Plant), Human Resource Management Journal Vol. 2 No. 1, pp. $42-59$.

Mahmoud, Q. H., Lescisin, M. and AlTaei, M., (2019), "Research challenges and opportunities in blockchain and cryptocurrencies", Internet Technology Letters, Vol. 2 No. 2), pp. 1 - 
6.

Mani, Z. and Chouk, I., (2018), "Consumer Resistance to Innovation in Services: Challenges and Barriers in the Internet of Things Era", Journal of Product Innovation Management, Vol. 35 No. 5, pp. 780-807.

Manski, S., (2017), "Building the blockchain world: Technological commonwealth or just more of the same?", Strategic Change, Vol 26 No. 5, pp. 511-522.

Maroufkhani, P., Tseng, M.L., Iranmanesh, M., Ismail, W. K. Wan. and Khalid, Haliyana., (2020), "Big data analytics adoption: Determinants and performances among small to medium-sized enterprises", International Journal of Information Management, Vol. 54, p. 102190.

Martinez, V., Martinez, V., Zhao, M., Blujdea, C., Han, X., Neely, A. and Albores, Pavel., (2019), "Blockchain-driven customer order management", International Journal of Operations and Production Management, Vol. 39 No. 6/7/8, pp. 993-1022.

Meijer, d. and R.W, C., (2016), "The UK and Blockchain technology: A balanced approach", Journal of Payments Strategy and Systems, Vol. 9 No. 4, pp. 220-229.

Miau, S. and Yang, J.-M., (2018), "Bibliometrics-based evaluation of the Blockchain research trend: 2008 - March 2017", Technology Analysis and Strategic Management, Vol 30 No. 9, pp. 1029-1045.

Min, H., (2019), "Blockchain technology for enhancing supply chain resilience", $\underline{\text { Business }}$ Horizons, Vol. 62 No. 1, pp. 35-45.

Mohamad, M. and Songthaveephol, V., (2020), "Clash of titans: The challenges of sociotechnical transitions in the electrical vehicle technologies - the case study of Thai automotive industry", Technological Forecasting and Social Change, Vol. 153, pp. 119-772.

Moktadir, M. A., Dwivedi, A., Rahman, A., Jose, C., Jabbour, C., Paul, S. K., Sultana, R. and Madaan, J., (2020), "An investigation of key performance indicators for operational excellence towards sustainability in the leather products industry", Business Strategy and the Environment, pp. 1-21.

Morkunas, V. J., Paschen, J. and Boon, E., (2019), "How blockchain technologies impact your business model", Business Horizons, 62(3), pp. 295-306.

Morris, H., Harvey, C. and Kelly, A., (2009), "Journal rankings and the ABS Journal Quality Guide", Management Decision, Vol. 47 No. 9, pp. 1441-1451

Mortimer, J., (2005), "Jaguar "Roadmap" rethinks self-piercing technology. Industrial Robot: "The international journal of robotics research and application, Vol. 32 No. 3, pp. 209-213.

$\begin{array}{ccccc}\text { Nakamoto, } & \text { S., } & \text { (2008), "Bitcoin: } & \text { A } & \text { Peer-to-Peer Electronic Cash System" } \\ \text { m } & \text { available } & \text { at: } & \underline{\text { https://nakamotoinstitute.org/bitcoin/ }}\end{array}$ (Accessed 31 January 2019).

Nam, D., Lee, J. and Lee, H., (2019), "Business analytics adoption process: An innovation diffusion perspective", International Journal of Information Management, Vol. 49,pp. 411-423.

Natalicchio, A., Ardito, L., Savino, T. and Albino, V., (2017), "Managing knowledge assets for open innovation: a systematic literature review", Journal of Knowledge Management, Vol. 21 No. 6, pp. 1362-1383.

Nolan, C. T. and Garavan, T. N., (2016), "Human Resource Development in SMEs: A Systematic Review of the Literature", International Journal of Management Reviews, Vol. 18 No. 1, pp. 85-107.

O'Dair, M. and Beaven, Z., (2017), "The networked record industry: How blockchain 
technology could transform the record industry", Strategic Change, Vol. 26 No. 5, pp. 471-480.

O'Dair, M. and Owen, R., (2019), "Financing new creative enterprise through blockchain technology: Opportunities and policy implications",Strategic Change, Vol. 28 No. 1, pp. 9-17.

Oh, J. and Shong, I., (2017), "A case study on business model innovations using Blockchain: focusing on financial institutions", Asia Pacific Journal of Innovation and Entrepreneurship, Vol. 11 No. 3, pp. 335-344.

O'Leary, D. E., (2017), "Configuring blockchain architectures for transaction information in blockchain consortiums: The case of accounting and supply chain systems", Intelligent Systems in Accounting, Finance and Management, Vol. 24 No. 4, pp. 138-147.

O'Leary, D. E., (2018), "Open Information Enterprise Transactions: Business Intelligence and Wash and Spoof Transactions in Blockchain and Social Commerce" Intelligent Systems in Accounting, Finance and Management, Vol. 25 No. 3, pp. 148-158.

Olhager, J. and Person, F., (2006), "Simulating production and inventory control systems: a learning approach to operational excellence", Production Planning and Control, Vol. 17 No. 2, pp. 113-127.

Orji, I. J., Kusi-Sarpong, S., Huang, S. \& Vazquez-Brust, D., (2020), "Evaluating the factors that influence blockchain adoption in the freight logistics industry", Transportation Research Part E: Logistics and Transportation Review, Vol. 141, pp. 102-025.

Patil, P., Tamilmani, K., Rana, N. P. and Raghavan, V., (2020), "Understanding consumer adoption of mobile payment in India: Extending Meta-UTAUT model with personal innovativeness, anxiety, trust, and grievance redressal", International Journal of Information Management, Vol. 54, pp. 102-144.

Pazaitis, A., Filippi, P. D. and Kostakisa, V., (2017), "Blockchain and value systems in the sharing economy: The illustrative case of Backfeed", Technological Forecasting and Social Change, Vol. 125, pp. 105-115.

Pólvora, A., Nascimento, S., Lourenço, J. S. and Scapolo, F., (2020.), "Blockchain for industrial transformations: A forward-looking approach with multi-stakeholder engagement for policy advice", Technological Forecasting and Social Change, Vol. 157, pp. 120-091.

Power, B., (2013), "Operational Excellence, Meet Customer Intimacy", $\underline{\text { Harvard Business }}$ Review.

Puklavec, B., Oliveira, T. and Popovič, A., (2020), "Understanding the determinants of business intelligence system adoption stages: An empirical study of SMEs", Industrial Management and Data Systems, Vol. 118 No. 1, pp. 236-261.

Qamar, A. and Hall, M., (2018), "Can Lean and Agile organisations within the UK automotive supply chain be distinguished based upon contextual factors?", Supply Chain Management: An International Journal, Vol. 23 No. 3, pp. 239-254.

Queiros, M. M. and Wamba, S. F., (2019), "Blockchain adoption challenges in supply chain: An empirical investigation of the main drivers in India and the USA", International Journal of Information Management, Vol. 4, pp. 70-82.

Queiroz, M. M., Telles, R. and Bonilla, S. H, (2019), "Blockchain and supply chain management integration: a systematic review of the literature", Supply Chain Management: An International Journal, pp. 1-15.

Saberi, S., Kouhizadeh, M., Sarkis, J. and Shen, L., (2018), "Blockchain technology and its relationships to sustainable supply chain management", International Journal of Production Research, Vol. 57 No. 7, pp. 2117-2135. 
Sanders, F., Semeijn, J. and Mahr, D., (2018), "The acceptance of blockchain technology in meat traceability and transparency", British Food Journal, Vol. 120 No. 9, pp. 20662079.

Santa, R., Hyland, P. and Ferrer, M., (2014), "Technological innovation and operational effectiveness: their role in achieving performance improvements", Production Planning and Control, Vol. 25 No. 12, pp. 969-979.

Schuetz, S. and Venkatesh, V., (2019), "Blockchain, adoption, and financial inclusion in India: Research opportunities", International Journal of Information Management, In Press(Corrected Proof), pp. 101-936.

Scott, B., Loonam, J. and Kumar, V., (2017), "Exploring the rise of blockchain technology: Towards distributed collaborative organizations", Strategic Change, Vol. 26 No. 5, pp. 423-428.

Sharma, P. K., Kumar, N. and Park, J. H., (2018), "Blockchain-based DistributedFramework for Automotive Industry in a Smart City", IEEE Transactions on Industrial Informatics, pp. 1 - 9.

Shaw, B. G. D., (1989)," The application of statistical process control in U.K. automotive manufacture: Some research findings", Quality and Reliability Engineering International, Vol. 5 No. 1, pp. 5-15.

Shermin, V., (2017), "Disrupting governance with blockchains and smart contracts",Strategic Change, 26(5), pp. 499-509.

Sheth, A. and Subramanian, H., (2019), "Blockchain and contract theory: modeling smart contracts using insurance markets", Managerial Finance, ahead-of-print(ahead-ofprint), pp. 1-12.

Siegfried, N., Rosenthal,, T. and Benlian, A., (2020), "Blockchain and the Industrial Internet of Things: A requirement taxonomy and systematic fit analysis", Journal of Enterprise Information Management, ahead-of-print(ahead-of-print), pp. 1-23.

Siew, E.-G., Rosli, K. and Yeow, P. H., (2020), "Organizational and environmentalinfluences in the adoption of computer-assisted audit tools and techniques (CAATTs) by audit firms in Malaysia", International Journal of Accounting Information Systems, Vol. 36, p. 100445.

SMMT, (2018a), "UK CV manufacturing up in July as exports boost output", available at: https://www.smmt.co.uk/2018/08/uk-cv-manufacturing-up-in-july-asexports-boost-output/(Accessed 28 January 2018).

SMMT, (2018b), "New automotive tech challenge helps shape future of mobility", [ available at: https://www.smmt.co.uk/2018/10/new-automotive-tech-challengehelps-shape-future-of-mobility/ (Accessed 20 May 2019).

SMMT, (2019), "2018 Automotive Sustainability Report", available at: https://www.smmt.co.uk/industry-topics/sustainability/employment/ (Accessed 22 June 2019).

Sony, M., (2019), "Implementing sustainable operational excellence in organizations: an integrative viewpoint", Production and Manufacturing Research, Vol. 7 No 1, pp. 6787 .

Srivastava, S. K., (2007), "Green supply-chain management: A state-of-the-art literature review", International Journal of Management Reviews, Vol. 9 No. 1, pp. 53-80.

Steininger, D. M., (2019), "Linking information systems and entrepreneurship: A review and agenda for IT-associated and digital entrepreneurship research", Information Systems Journal, Vol. 29 No. 2, pp. 363-407.

Swarnaker, V. \& Vinodh, S., (2016), "Deploying Lean Six Sigma framework in an automotive 
component manufacturing organization", International Journal of Lean Six Sigma, Vol. 7 No. 3, pp. 267-293

Tang, O. \& Musa, S. N., (2011). "Identifying risk issues and research advancements in supply chain risk management", International Journal of Production Economics, Vol. 133 No. 1, pp. 25-34.

Tang, Y., Xiong, J., Becerril-Arreola, R. amd Iyer , ,. L., (2020), "Ethics of blockchain: A framework of technology, applications, impacts, and research directions", Information Technology and People, ahead-of-print(ahead-of-print), pp. 1-31.

Thurner, T., (2018), "Supply chain finance and blockchain technology - the case of reverse securitisation", Foresight, Vol. 20 No. 4, pp. 447-448.

Tian, M., Deng, P., Zhang, Y. and Salmador, M. P., (2018), How does culture influence innovation? A systematic literature review", Management Decision, Vol. 56 No. 5, pp. 1088-1107.

Tiscini, R., Testarmata, S., Ciaburri,, M. and Ferrari , E., (2020), "The blockchain as a sustainable business model innovation", Management Decision, ahead-of-print No(ahead-of-print No), pp. 1-22.

Tornatzky, L. G. and Fleischer, M., (1990), "The Process of Technology Innovatio", Lexington, MA: Lexington Books.

Tranfield, D., Denyer, D. and Smart, P., 2003. Towards a Methodology for Developing Evidence-Informed Management Knowledge by Means of Systematic Review. British Journal of Management, Vol. 14 No. 3, pp. 207-222.

Treacy, M. \& Wiersema, F., (1993), "Customer Intimacy and Other Value Discipline", available at: https://hbr.org/1993/01/customer-intimacy-and-other-value-disciplines (Accessed 20 May 2019).

Treiblmaier, H., (2018), "The impact of the blockchain on the supply chain: a theory-based research framework and a call for action", Supply Chain Management: An International Journal, Vol. 23 No. 6, pp. 545-559.

Tsolakis, N., Niedenzu, D., Simonetto, M., Dora, M. and Kumar, M., (2020), "Supply network design to address United Nations Sustainable Development Goals: A case study of blockchain implementation in Thai fish industry", Journal of Business Research, Vol. 30, pp. 1-25.

Turnbull, P. J., (1988), "The limits to'Japanisation'-Just-in-Time, labour relations and the UK automotive industry", New Technology, Work and Employment, Vo. 3 No. 1, pp. 720 .

Turnbull, P., Oliver, N. and Wilkinson, B., (1992), "Buyer-supplier relations in the UK automotive industry: Strategic implications of the Japanese manufacturing model", Strategic Management Journal, Vol. 13 No. 2, pp. 159-168.

Turner, K. and Williams, G., (2005), "Modelling complexity in the automotive industry supply chain", Journal of Manufacturing Technology Management, Vol. 16 No. 4, pp. 447458.

Upadhyay, N., (2020), "Demystifying blockchain: A critical analysis of challenges, applications and opportunities", International Journal of Information Management, Vol. 54, pp. 102-120.

Vincent, N. E., (2020), "Blockchain architecture: A design that helps CPA firms leverage the technology", International Journal of Accounting Information Systems, pp. 100-466.

Vrellas, C. G. and Tsiotras, G., (2015), "Quality management in the global brewing industry", International Journal of Quality and Reliability Management, Vol. 32 No. 1, pp. 4252. 
Wang, L., Luo, X., and Lee, F., (2019), "Unveiling the interplay between blockchain and loyalty program participation: A qualitative approach based on Bubichain", International Journal of Information Management, Vol. 49, pp. 397-410.

Wang, X., Zeng, D., Dai, H. \& Zhu, Y., (2020), "Making the right business decision: Forecasting the binary NPD strategy in Chinese automotive industry with machine learning methods", Technological Forecasting and Social Change, Vol. 151, pp. 120032.

Wang, Y., Hugh Han, J. and Beynon-Davies, P., (2019a), "Understanding blockchain technology for future supply chains: a systematic literature review and research agenda", Supply Chain Management: An International Journal, Vol. 24 No. 1, pp. 6284.

Wang, Y., Singgih, M., Wang, J. and Rit, M., (2019), "Making sense of blockchain technology: How will it transform supply chains?" International Journal of Production Economics, Vol. 211, pp. 221-236.

Warkentin, M. and Orgeron, C., (2020), "Using the security triad to assess blockchain technology in public sector applications", International Journal of Information Management, 0(0), pp. 102-090.

White, G. R., (2017), "Future applications of blockchain in business and management: A Delphi study" Strategic Change, Vol. 26 No. 5, pp. 439-451.

White, R., Marinakis, Y., Islam, N. and Walsh, S., (2020), "Is Bitcoin a currency, a technologybased product, or something else?", Technological Forecasting and Social Change, Vol. 151, pp. 119-877.

Wong, C., Skipworth, H., Godsell, J. and Achimugu, N., (2012) Towards a theory of supply chain alignment enablers: a systematic literature review", Supply Chain Management: An International Journal, Vol. 17 No. 4, pp. 419-437.

Yeoh, P., (2017), "Regulatory issues in blockchain technology", Journal of Financial Regulation and Compliance, Vol. 25 No. 2, pp. 196-208.

Ying, W., Jia, S. and Du, W., (2018), "Digital enablement of blockchain: Evidence from HNA group", International Journal of Information Management, Vol. 39, pp. 1-4.

Yin, H. H. S., Langenheldt, K., Harlev, M. and Mukkamala, R. R., (2019), "Regulating Cryptocurrencies: A Supervised Machine Learning Approach to De-Anonymizing the Bitcoin Blockchain" Journal of Management Information Systems, Vol. 36 No.

Yuan, Y. \& Wang, F.-Y., (2018), "Blockchain and Cryptocurrencies: Model, Techniques, and Applications", IEEE Transactions on Systems Man and Cybernetics Part C, Vol. 48 No. 9, pp. $1421-1428$.

Yusof, S. M. \& Aspinwall, E., (2001), "Case studies on the implementation of TQM in the UK automotive SMEs", International Journal of Quality and Reliability Management, Vol. 18 No. 7, pp. $722-744$.

Zhang, L., Xie, Y., Zheng, Y., Xue, W., Zheng, X. and Xu, X.,(2020), "The challenges and countermeasures of blockchain in finance and economics", Systems Research and Behavioral Science, Vol. 37 No. 4, pp. 691-698.

Zimmermann, R., Ferreira, L. M. D. and Moreira, A. C., (2016), "The influence of supply chain on the innovation process: a systematic literature review", Supply Chain Management: An International Journal, Vol. 21 No. 3, pp. 289-304. 